\title{
MID - TERM POST-OPERATIVE OUTCOME OF SINUS VENOSUS ATRIAL SEPTAL DEFECT WITH ANOMALOUS PULMONARY VENOUS CONNECTION WITH DIFFERENT SURGICAL STRATEGIES AND THEIR EFFECT ON SINUS NODE FUNCTION AND LATE VENOUS OBSTRUCTION.
}

Vishal V. Bhende ${ }^{1}$, Tanishq S. Sharma ${ }^{2}$, Deepakkumar V. Mehta ${ }^{3}$, Bhadra Y. Trivedi ${ }^{4}$, Amit Kumar ${ }^{5}$, Viral B. Patel ${ }^{6}$, Gurpreet Panesar ${ }^{7}$, Kunal Soni ${ }^{8}$, Kartik Dhami ${ }^{7}$, Nirja Patel $^{9}$, Sohilkhan R Pathan ${ }^{10}$, and Hardil P. Majmudar ${ }^{11}$

${ }^{1}$ Consultant,Pediatric Cardiac Surgery,Bhanubhai and Madhuben Patel Cardiac

Centre,Shree Krishna Hospital,Karamsad,Anand,Gujarat-388 325,India.

${ }^{2}$ Corresponding Author,Pediatric Cardiac Surgery,Bhanubhai and Madhuben Patel Cardiac Centre,Karamsad,Gujarat -388 325,India.

${ }^{3}$ Professor \& Head,Department of Radiodiagnosis \& Imaging,Pramukhswami Medical College \& Shree Krishna Hospital,Bhaikaka University,Karamsad,Anand,Gujarat -388

325,India.

${ }^{4}$ Consultant,Pediatric Interventional Cardiologist,Bhanubhai and Madhuben Patel Cardiac Centre,Shree Krishna Hospital,Karamsad,Anand,Gujarat-388 325,India.

${ }^{5}$ Consultant,Pediatric Cardiac Intensivist,Bhanubhai and Madhuben Patel Cardiac Centre,Karamsad,Anand,Gujarat-388 325,India

${ }^{6}$ Professor,Department of Radiodiagnosis \& Imaging,Pramukhswami Medical College \& Shree Krishna Hospital,Bhaikaka University,Karamsad,Anand,Gujarat -388 325,India.

${ }^{7}$ Consultant,Cardiac Anaesthesiology,Bhanubhai and Madhuben Patel Cardiac

Centre,Shree Krishna Hospital,Karamsad,Anand,Gujarat - 388 325,India.

${ }^{8}$ Consultant,Cardiac Anaesthesiology,Bhanubhai and Madhuben Patel Cardiac

Centre,Shree Krishna Hospital,Karamsad,Anand,Gujarat -388 325,India.

${ }^{9}$ Fellow,Cardiac Anaesthesiology,Bhanubhai and Madhuben Patel Cardiac Centre,Shree Krishna Hospital,Karamsad,Anand,Gujarat-388 325,India.

${ }^{10}$ Clinical Research Co-ordinator,Bhanubhai and Madhuben Patel Cardiac Centre,Shree Krishna Hospital,Karamsad,Anand,Gujarat -388 325,India.

${ }^{11}$ Bhanubhai and Madhuben Patel Cardiac Centre

January 20, 2022

\section{Introduction}

Sinus venosus atrial septal defects (SVASDs), originally described in 1858, account for approximately 4\%$11 \%$ of all atrial septal defects (ASDs) [1,2]. The typical SVASD is an interatrial communication that results from a deficiency of the common wall between the superior vena cava (SVC) and the right-sided pulmonary 
veins [2,3]. SVASD is commonly associated with anomalous pulmonary venous connections (APVCs) involving some or all of the pulmonary veins [3,4], which produces additional left-to-right shunting. The basic principle of repair is redirection of the APVC through the interatrial communication into the left atrium.

In contrast to operative repair of secundum ASD, the surgical approach for SVASD is more complex and carries the risk of stenosis of the SVC or pulmonary veins, residual shunting, and sinus node dysfunction[4].

We reviewed outcomes for patients who underwent SVASD repair at Bhanubhai and Madhuben Patel Cardiac Centre, Karamsad, Anand, Gujarat, India, with a focus on patient survival and development of arrythmias.

\section{Materials \& Methods}

The Institutional Ethics Committee (IEC-2) of the Bhanubhai and Madhuben Patel Centre for Medical Care and Education, Anand, Gujarat, India, approved this study (Approval number - IEC/BU/2021/Cr.48/283).

We identified 10 patients from our computerized cardiovascular database (FTP 192.168.0.5) who underwent primary surgical repair of SVASD between December 2018 and October 2021 (Table1). Their mean age was 3.7 years (median, 3.5; range, 1-8 years). Seven patients were boys and 3 were girls. One patient (P10) had left upper PAPVC without SVASD and was included in the study for purposes of comparison.

Drainage of the PAPVC was directly to the right atrium-superior vena cava (RA-SVC) junction in the 9 patients with SVASDs; in the other patient (P10), the left upper lobe of the lung exhibited partial anomalous venous drainage through a vertical vein, which in turn drained into the brachiocephalic vein; this scenario was suggestive of partial anomalous pulmonary venous drainage (PAPVD).

TABLE - 1

MATRIX OF THE STUDY POPULATION UNDERGOING SINUS VENOSUS - ATRIAL SEPTAL DEFECT REPAIR BY VARIOUS TECHNIQUES

\begin{tabular}{|c|c|c|c|c|c|c|c|c|c|}
\hline \multirow[b]{4}{*}{ SR.NO. } & \multirow{3}{*}{\multicolumn{2}{|c|}{ PATIENAGE }} & \multirow[b]{4}{*}{ SEX } & & \multirow[b]{4}{*}{$\begin{array}{l}\text { CPB } \\
\text { TIME }\end{array}$} & \multirow[b]{4}{*}{$\begin{array}{l}\text { ACC } \\
\text { TIME }\end{array}$} & \multirow{2}{*}{\multicolumn{2}{|c|}{$\begin{array}{l}\text { INTRA } \\
\text { OPERA } \\
\text { IN- } \\
\text { HOSPITAA- }\end{array}$}} & $\begin{array}{l}2-\mathrm{D} \\
\text { ECHO } \\
\text { CAR- } \\
\text { TIDVE- }\end{array}$ \\
\hline & & & & & & & & & $\begin{array}{l}\text { GRA- } \\
\text { PHY }\end{array}$ \\
\hline & & & & & & & TECHNISILAEY & SIVE & $\mathrm{AT}$ \\
\hline & $\begin{array}{l}\text { PRO- } \\
\text { FILE }\end{array}$ & $\begin{array}{l}\text { @ RE- } \\
\text { PAIR }\end{array}$ & & WEIGH'SVC & & & $\begin{array}{l}\text { EM- FROM } \\
\text { PLOYEDDOSX }\end{array}$ & $\begin{array}{l}\text { PRES- } \\
\text { SURES }\end{array}$ & $\begin{array}{l}\text { DIS- } \\
\text { CHARG }\end{array}$ \\
\hline \multirow[t]{11}{*}{1} & Miss D & 4 Years & Female & Single & 104 & 71 & Sandwich 5 Days & SVC & Flow \\
\hline & $\{P 1\}$ & & & kgs. & Min. & Min. & & $16 / 13(15)$ & acceler- \\
\hline & & & & & & & Single- & $\mathrm{mm} \mathrm{Hg}$ & ation \\
\hline & & & & & & & Patch & SVC- & at SVC \\
\hline & & & & & & & & & $\begin{array}{l}\text { to RA } \\
\text { junc- }\end{array}$ \\
\hline & & & & & & & & tion 15 & tion \\
\hline & & & & & & & & $\mathrm{mm} \mathrm{Hg}$ & with \\
\hline & & & & & & & & Mid- & gradi- \\
\hline & & & & & & & & $\mathrm{RA}$ & ent of \\
\hline & & & & & & & & cavity & $4 / 2$ \\
\hline & & & & & & & & $\begin{array}{l}11 / 04(08) \\
\mathrm{mm} \mathrm{Hg}\end{array}$ & $\begin{array}{l}(\mathrm{peak} / \mathrm{m} \\
\mathrm{mm} \mathrm{Hg}\end{array}$ \\
\hline
\end{tabular}




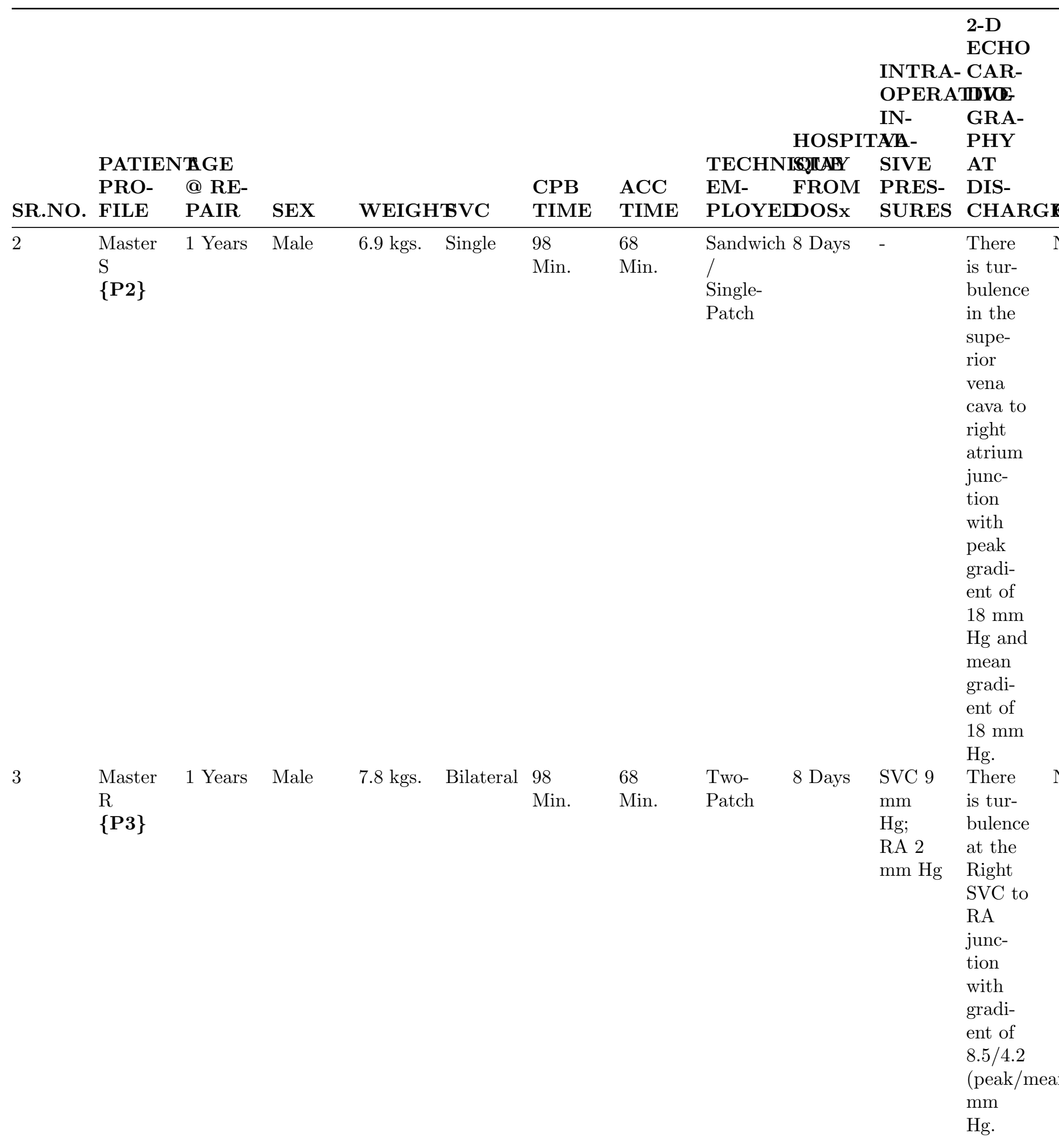




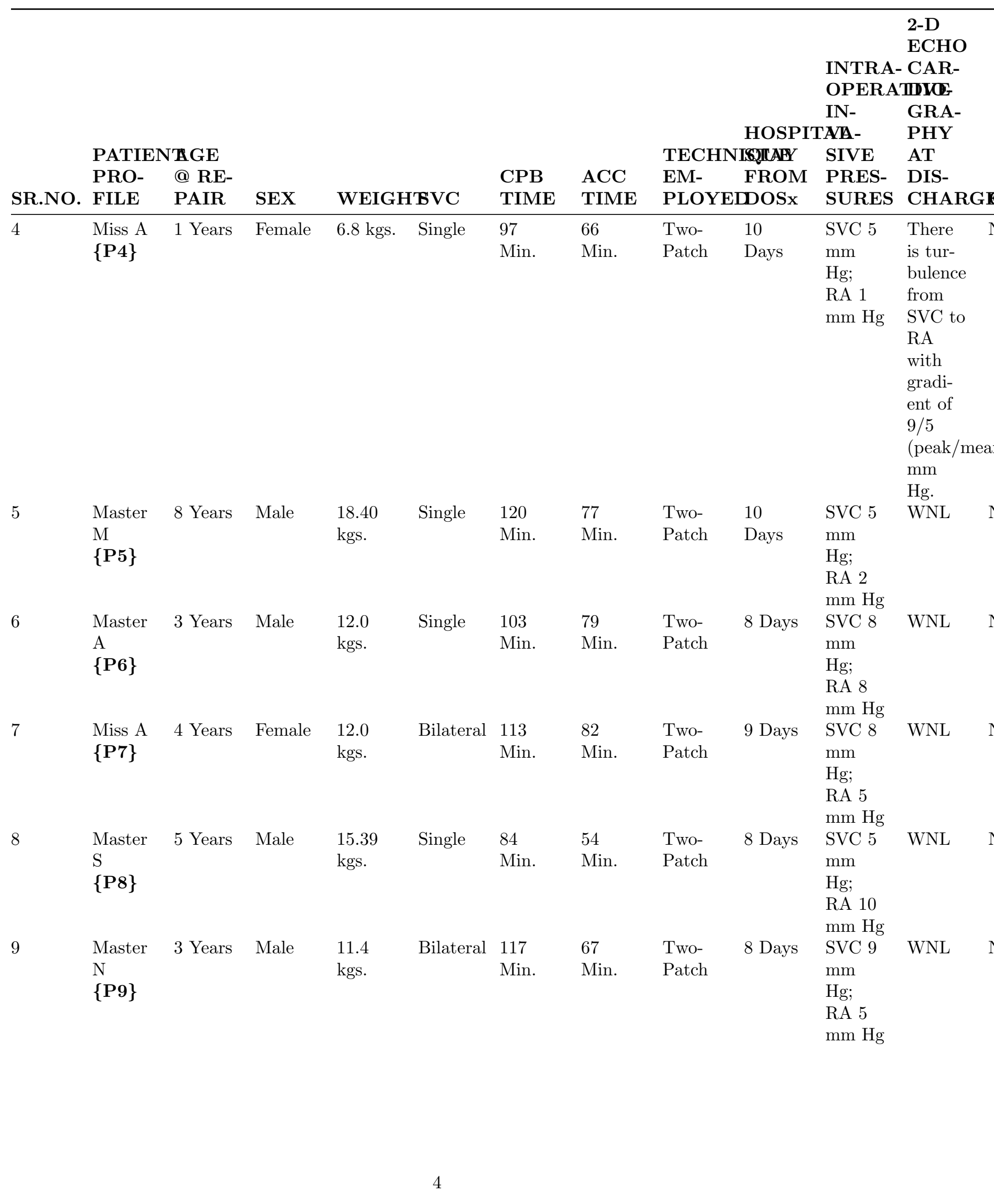




\begin{tabular}{|c|c|c|c|c|c|c|c|c|c|c|}
\hline \multirow[b]{4}{*}{ SR.NO. } & \multirow{3}{*}{\multicolumn{2}{|c|}{ PATIENTAGE }} & \multirow[b]{4}{*}{ SEX } & & & \multirow[b]{4}{*}{$\begin{array}{l}\text { CPB } \\
\text { TIME }\end{array}$} & \multirow[b]{4}{*}{$\begin{array}{l}\text { ACC } \\
\text { TIME }\end{array}$} & & \multicolumn{2}{|c|}{$\begin{array}{c}\text { 2-D } \\
\text { ECHO } \\
\text { INTRA- CAR- } \\
\text { OPERATIIY- }\end{array}$} \\
\hline & & & & & & & & HOSPI & IN- & $\begin{array}{l}\text { GRA- } \\
\text { PHY }\end{array}$ \\
\hline & & & & & & & & TECHNISSILAFY & SIVE & AT \\
\hline & $\begin{array}{l}\text { PRO- } \\
\text { FILE }\end{array}$ & $\begin{array}{l}\text { @ RE- } \\
\text { PAIR }\end{array}$ & & \multicolumn{2}{|c|}{ WEIGHTVC } & & & $\begin{array}{l}\text { EM- FROM } \\
\text { PLOYEDDOSX }\end{array}$ & $\begin{array}{l}\text { PRES- } \\
\text { SURES }\end{array}$ & $\begin{array}{l}\text { DIS- } \\
\text { CHARG }\end{array}$ \\
\hline \multirow[t]{9}{*}{10} & Master & 7 Years & Male & 20.0 & Single & 150 & 106 & 6 Days & - & WNL \\
\hline & $\mathrm{P}$ & & & kgs. & & Min. & Min. & PA- & & \\
\hline & $\{P 10\}$ & & & & & & & $\mathrm{PVC}$ & & \\
\hline & & & & & & & & Re- & & \\
\hline & & & & & & & & $\begin{array}{l}\text { routing } \\
+ \text { ASD }\end{array}$ & & \\
\hline & & & & & & & & Closure & & \\
\hline & & & & & & & & + Pul- & & \\
\hline & & & & & & & & monary & & \\
\hline & & & & & & & & Valvotomy & & \\
\hline
\end{tabular}

\section{N.B. :}

RA- Right Atrium, SVC - Superior Vena Cava, CPB - Cardio-pulmonary Bypass, ACC-Aortic Cross-clamp, PAPVC - Partial Anomalous Pulmonary Venous Connection, ASD - Atrial Septal Defect, WNL - Within Normal Limits

Codes for Patients - Miss D (P1), Master S (P2), Master R (P3), Miss A (P4), Master M (P5), Master A (P6),

Miss A(P7), Master S (P8), Master N (P9), Master P (P10)

ECHOCARDIOGRAPHIC DATA -

All 10 patients enrolled in the study underwent 2-D Echocardiography pre-operatively and also postoperatively at the time of discharge. 

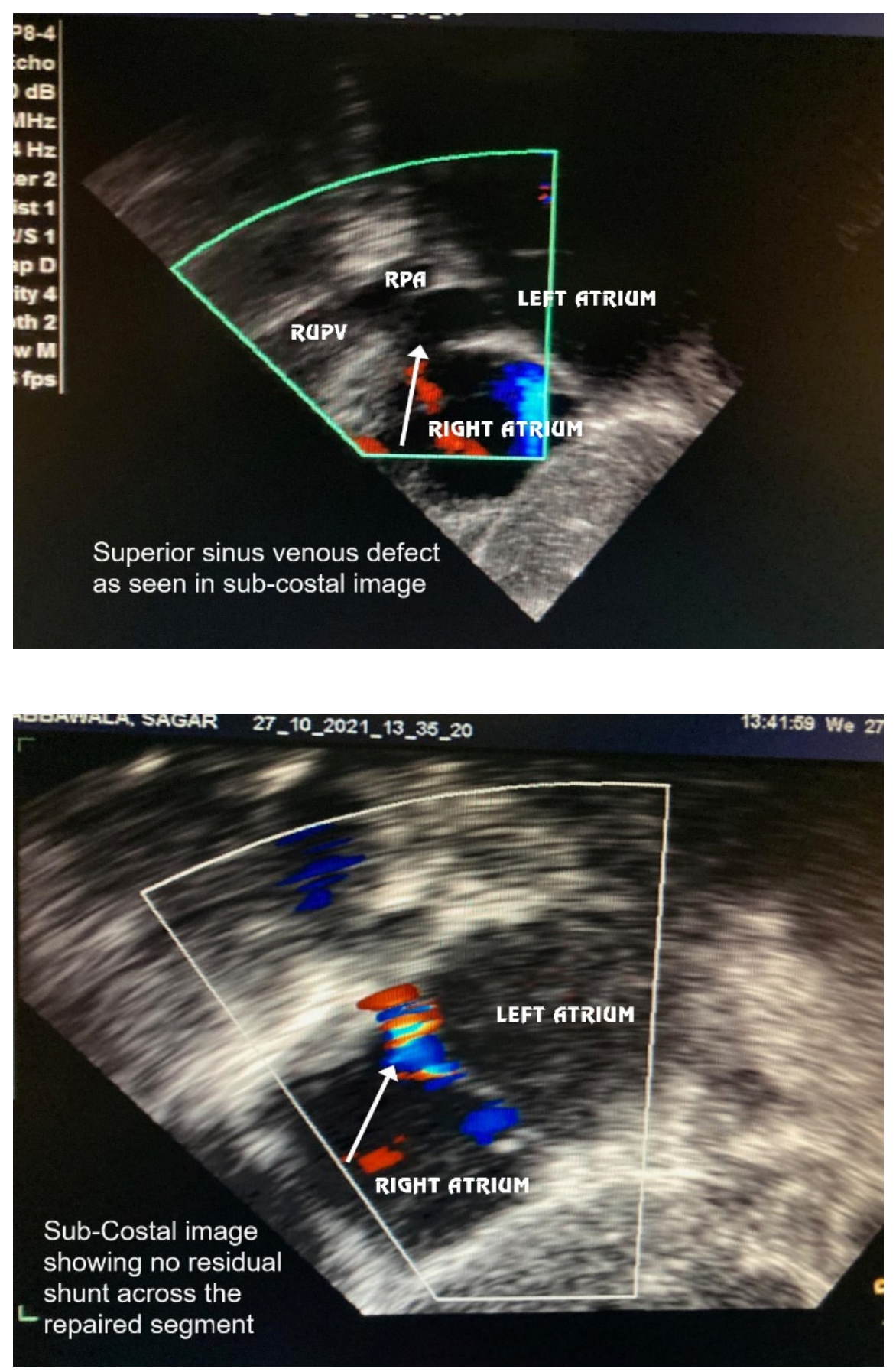

Figure 1 : PRE-OPERATIVE Figure 2 : POST-OPERATIVE 2-D ECHOCARDIOGRAPHY 2-D ECHOCARDIOGRAPHY FOR P 9 PATIENT FOR P 9 PATIENT 

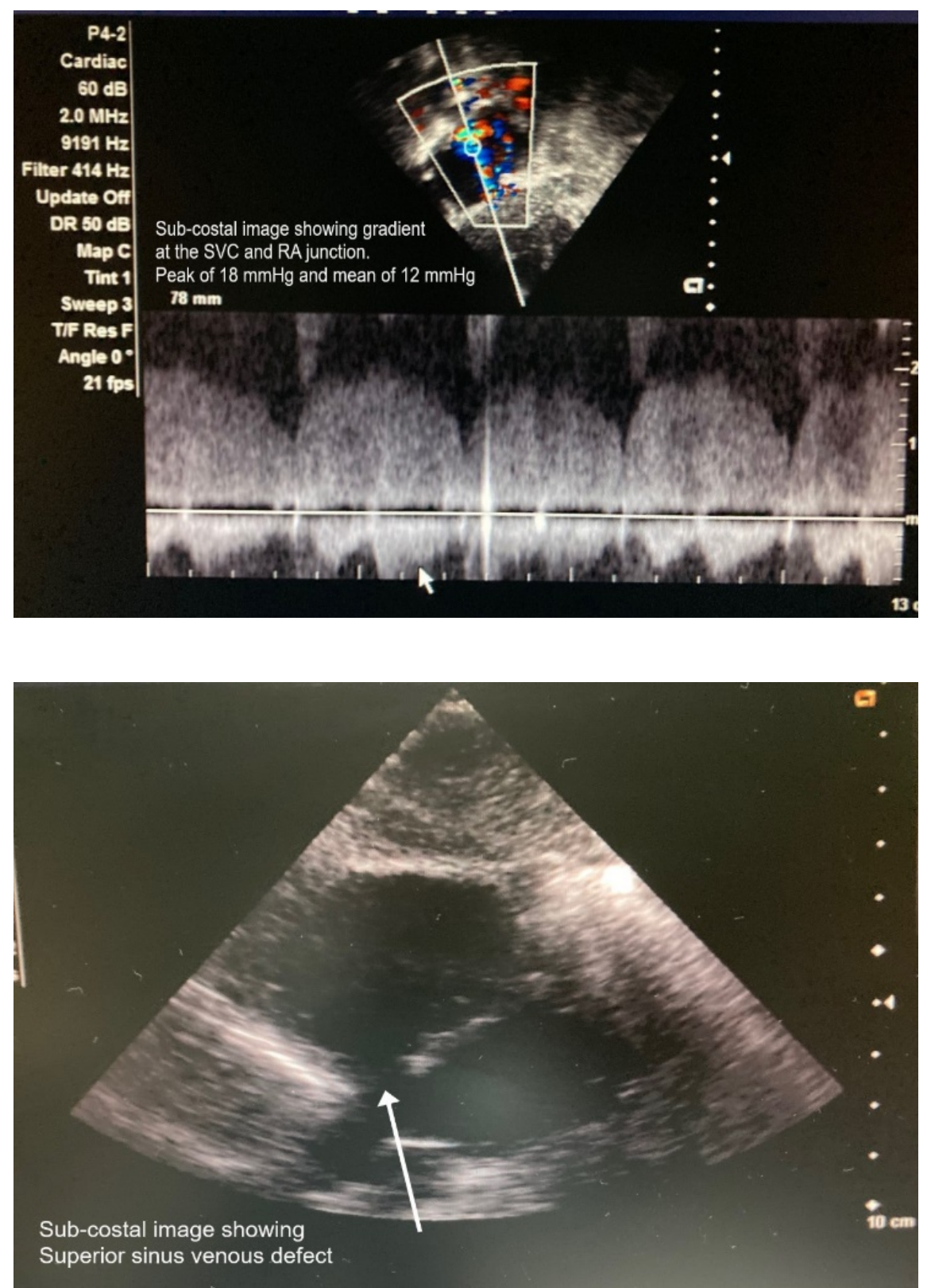

Figure 3 : PRE-OPERATIVE Figure 4 : POST-OPERATIVE

\section{2-D ECHOCARDIOGRAPHY 2-D ECHOCARDIOGRAPHY}

\section{FOR P 1 PATIENT FOR P 2 PATIENT}

(Image Credits, Figure $1-4$ : Dr.Bhadra Y. Trivedi)

Dynamic cardiac computed tomography

Dynamic cardiac computed tomography $(\mathrm{CT})$ was performed preoperatively in our series for two patients. In patient $\mathrm{P} 4$, intracranial arteriovenous malformations were strongly suspected of leading to dilatation of the SVC. Dynamic cardiac CT revealed a moderately large ASD (superior sinus venosus type; Figures5to 8). The right superior pulmonary vein drained into the terminal portion of the SVC. This scenario was 
suggestive of both PAPVC and PAPVD. The main, right, and left pulmonary arteries were dilated, which was suggestive of pulmonary arterial hypertension. The left vertebral artery arose directly from the aortic arch as a third branch. The proximal, middle, and distal diameters of the SVC each measured approximately $8.7 \mathrm{~mm}$.

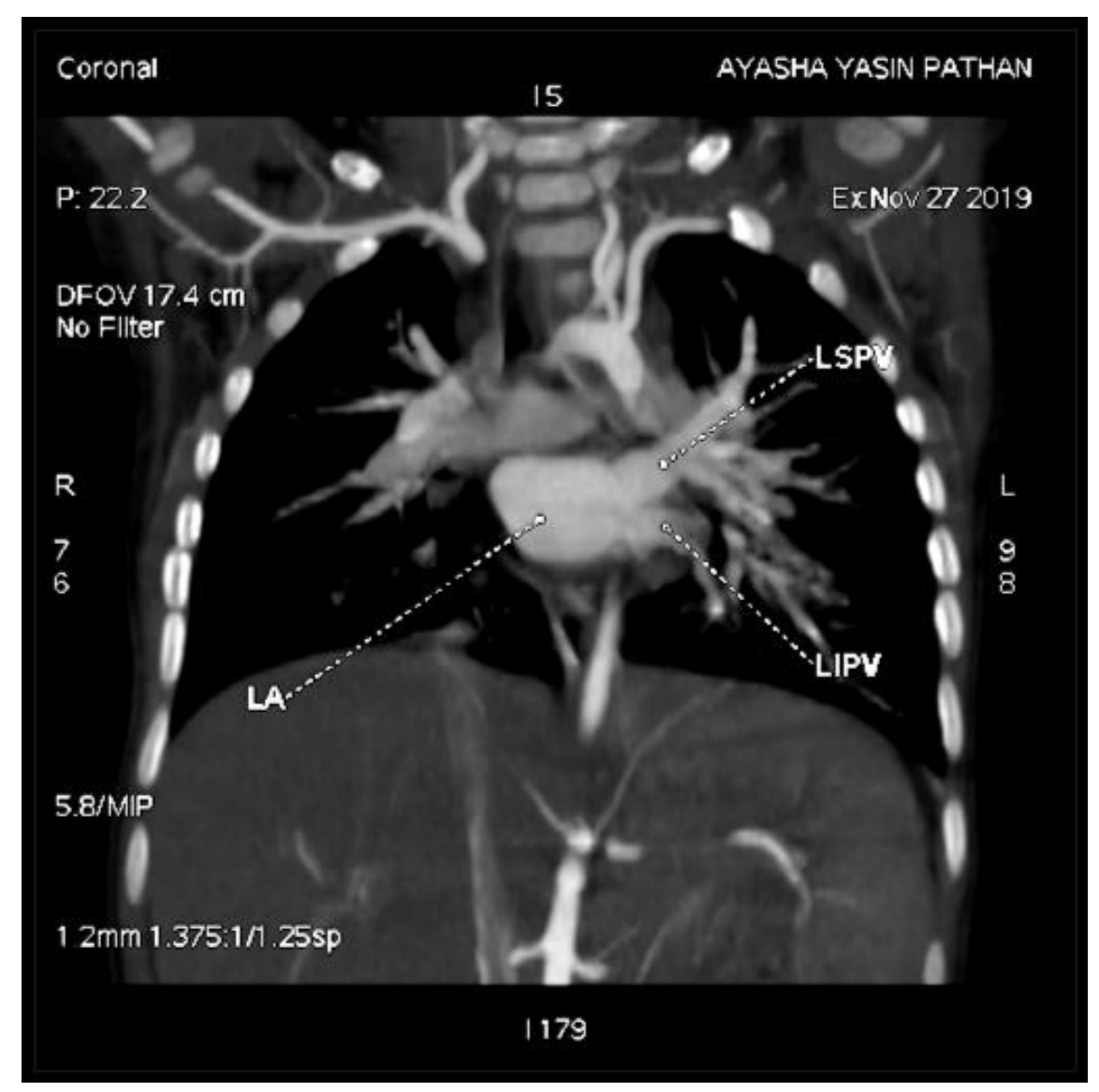




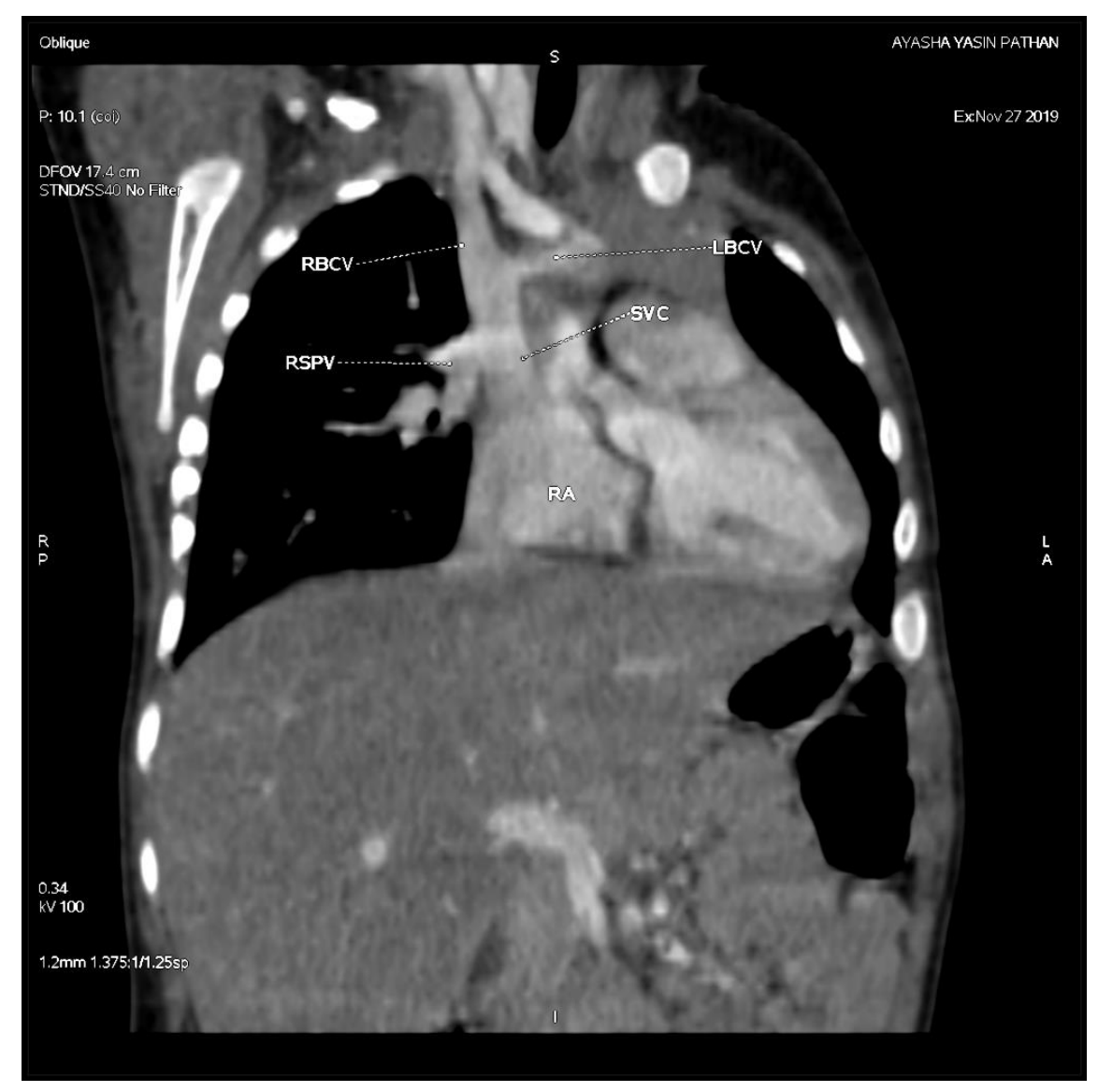

Figure 5 : MAXIMUM INTENSITY Figure 6 : MAXIMUM INTENSITY PROJECTION-CORONAL VIEW- PROJECTION-LA \& LSPV \& RSPV OPENING IN SVC IN P 4 LIPV-CORONAL VIEW IN P 4 PATIENT PATIENT 


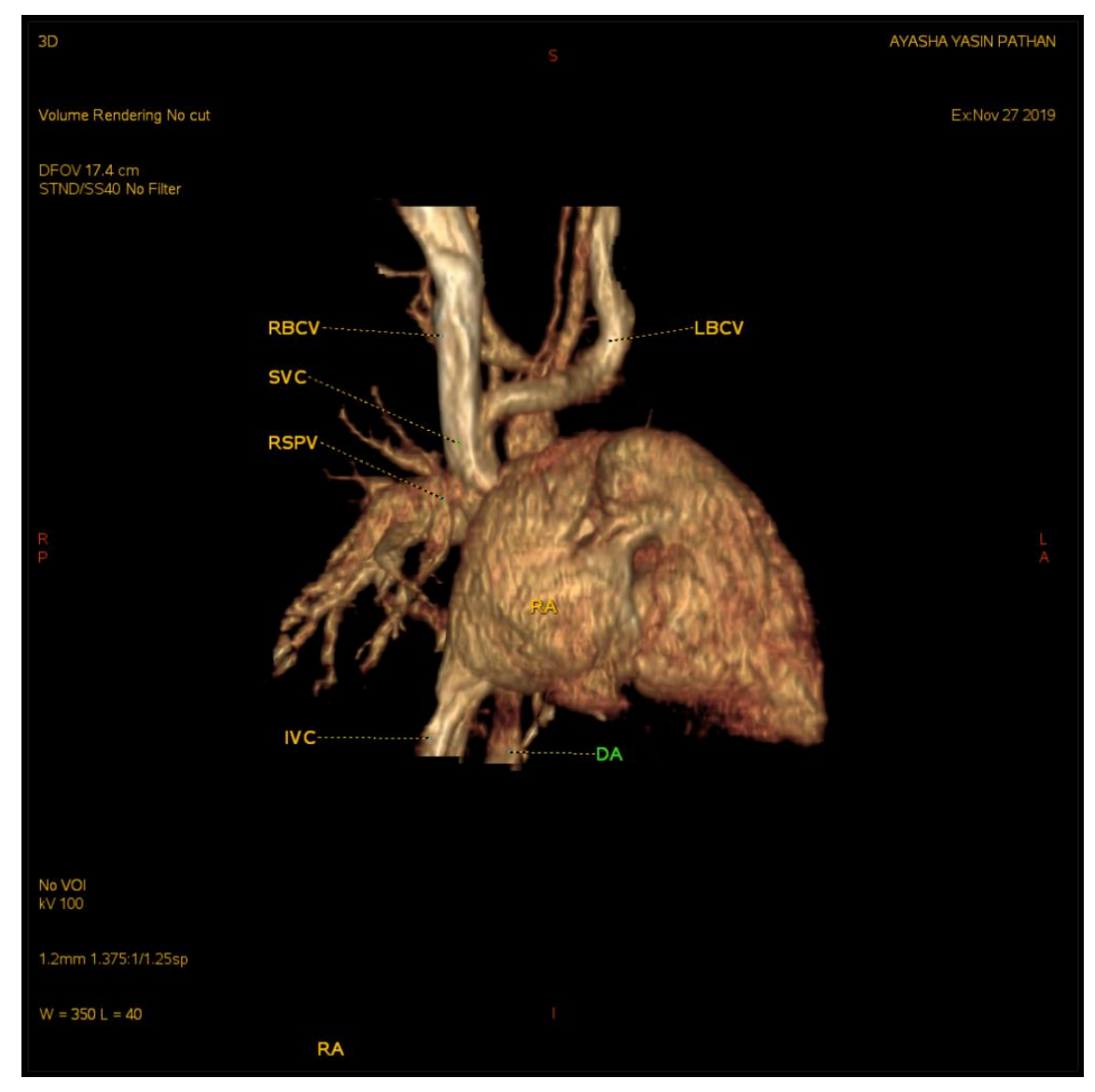




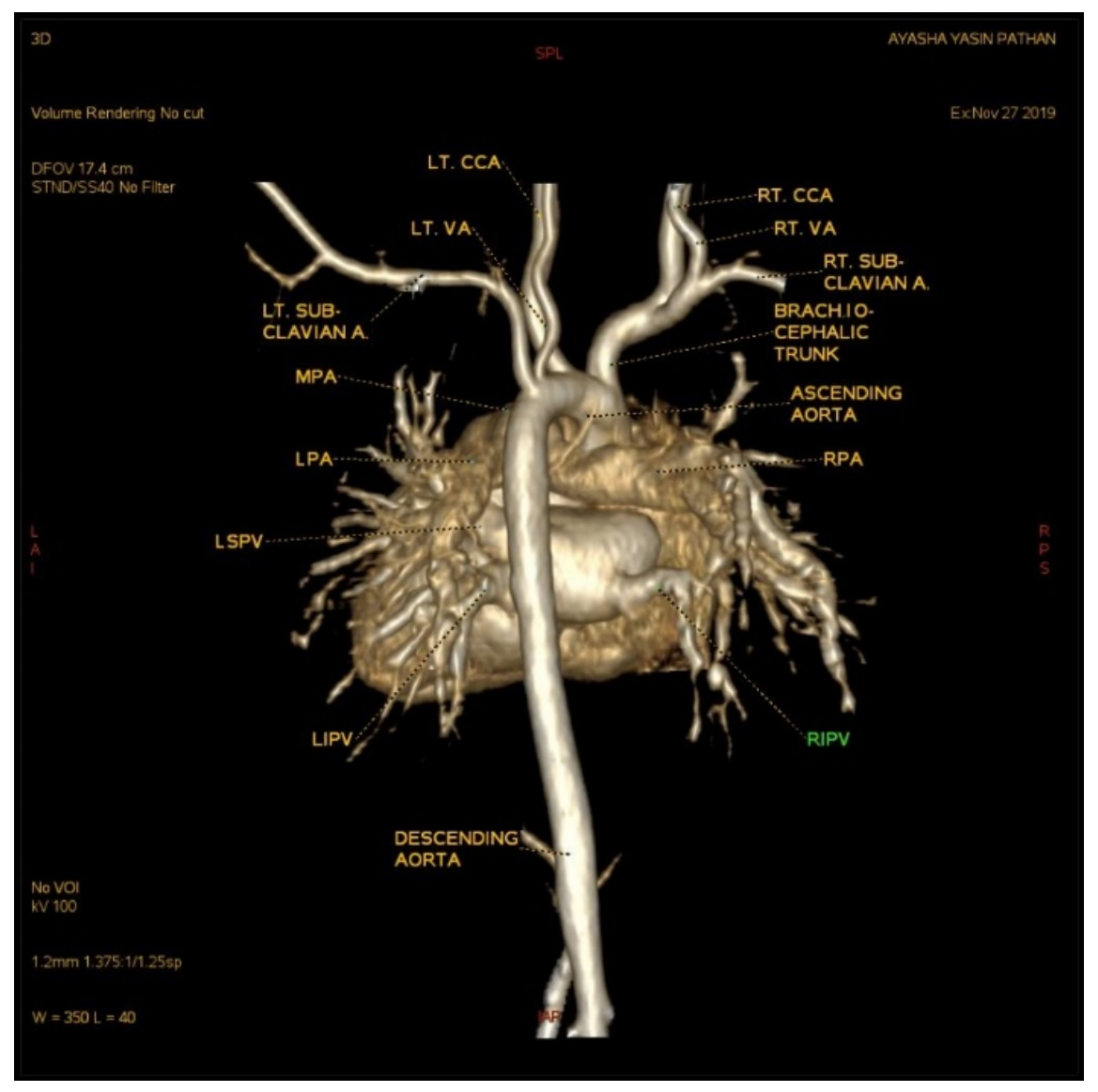

Figure 7 : VOLUME RENDERING- Figure 8 : VOLUME RENDERING-

\section{ANTERIOR VIEW - CT CARDIAC POSTERIOR VIEW - CT CARDIAC \\ DYNAMIC STUDY IN P 4 PATIENT DYNAMIC STUDY IN P 4 PATIENT}

(Image Credits, Figure 5-8: Dr.Deepakkumar V. Mehta)

In patient P10, left-sided partial pulmonary venous connection to the innominate vein was suspected, and cardiac CT and pulmonary angiography were performed to confirm this (Figures 9 and 10). Dynamic cardiac CT of the upper lobe of the left lung revealed partial anomalous venous drainage through a vertical vein, which in turn drained into the brachiocephalic vein; this scenario was suggestive of PAPVD. The hemiazygos vein drained posteriorly into an anomalous vertical vein at the lower border of the T4 vertebral level, which was $1.7 \mathrm{~cm}$ below the confluence of anomalous vertical vein and the brachiocephalic vein. The distance from the anomalous vein hilum to the opening of the hemiazygos vein was $1.3 \mathrm{~cm}$. The other three pulmonary veins drained into the left atrium. 


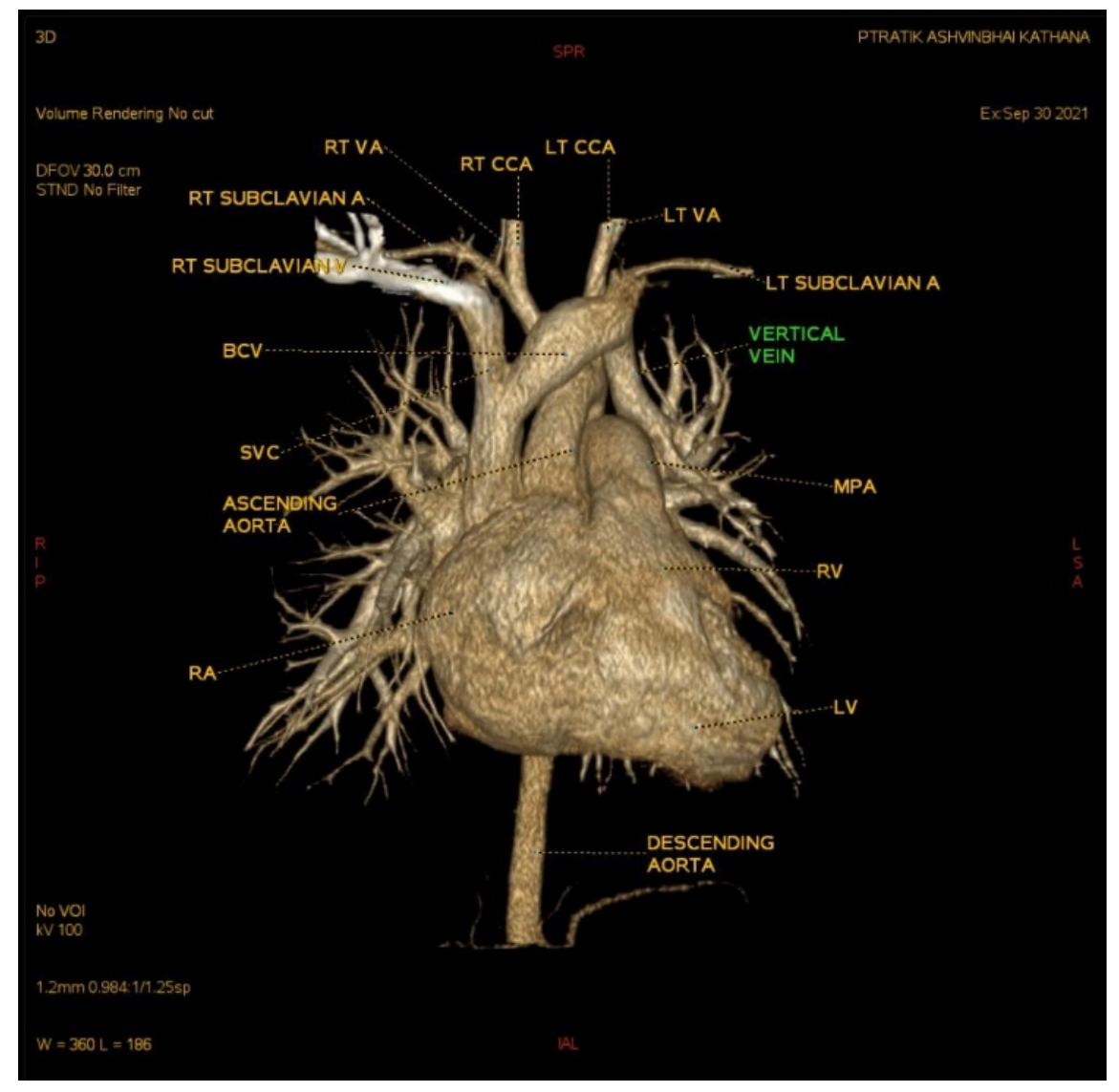

Figure 9 : VOLUME RENDERING-ANTERIOR VIEW - CT CARDIAC DYNAMIC STUDY IN P 10 PATIENT 


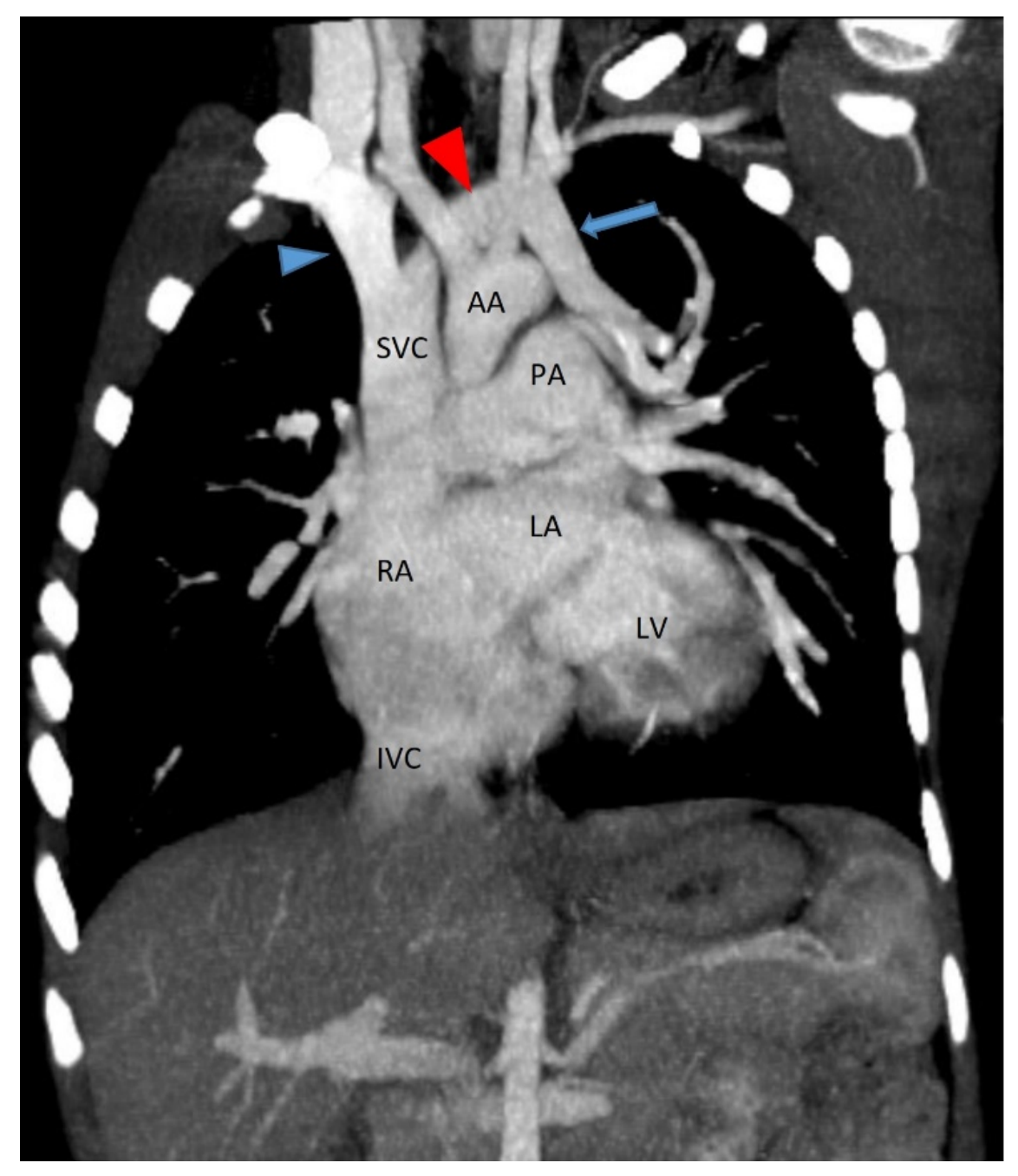

Figure 10 : MAXIMUM INTENSITY PROJECTION CORONAL VIEW - IN P 10

\section{PATIENT}

VERTICAL VEIN (BLUE ARROW) (PAPVD FROM LEFT UPPER LOBE OF LUNG) DRAINING INTO LEFT BRACHIOCEPHALIC VEIN (RED ARROW HEAD)

RIGHT BRACHIOCEPHALIC VEIN (BLUE ARROW HEAD)

AA: ARCH OF AORTA, SVC: SUPERIOR VENA CAVA, PA PULMONARY ARTERY, RA: RIGHT ATRIUM, LA LEFT ATRIUM, LV: LEFT VENTRICLE, IVC: INFERIOR VENA CAVA

(Image Credits, Figure $9-10$ : Dr.Viral B. Patel)

Surgical techniques

All procedures were performed through a median sternotomy. Cardiopulmonary bypass was used with bicaval cannulation in 7 patients and tricaval cannulation in 3 and with ascending aortic cannulation at moderate systemic hypothermia $(25 \mathrm{oC}-32 \mathrm{oC})$ in all patients.

We achieved cardioplegic arrest with Del Nido cardioplegia and topical slush saline. We did not routinely use a left ventricular vent. All patches were made from fresh autologous pericardium. In 2 patients (20\%), we 
performed single-patch/sandwich-patch repair of the SVASD with inclusion of the PAPVC and ASD closure; in $7(70 \%)$, we performed repair with two pericardial patches to enlarge the SVC-RA junction (Figures 11 to 12$)$.

Stenosis of the SVC and the right-sided pulmonary veins was graded as trivial, mild, moderate, or severe. Preoperative and postoperative electrocardiography (ECG) was performed in all 10 patients. Initial postoperative ECG was considered early, and ECG after hospital discharge was considered late.

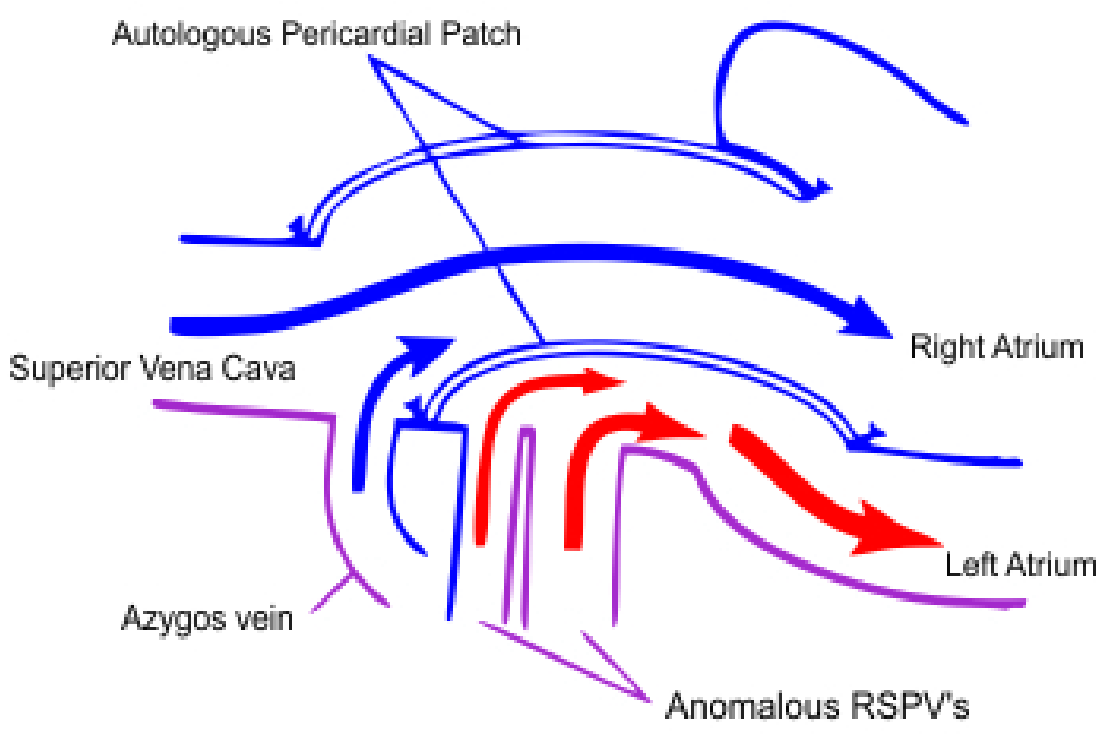

TWO-PATCH TECHNIQUE 


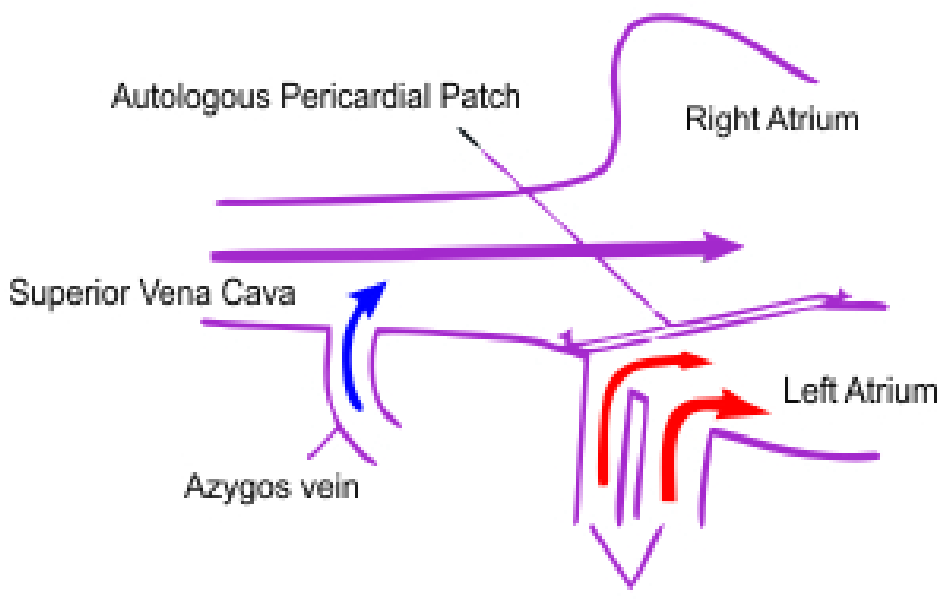

Anomalous RSPV's

SINGLE-PATCH / SANDWICH TECHNIQUE

Figure 11 : SINGLE - PATCH/ Figure 12 : TWO - PATCH TECHNIQUE SANDWICH TECHNIQUE

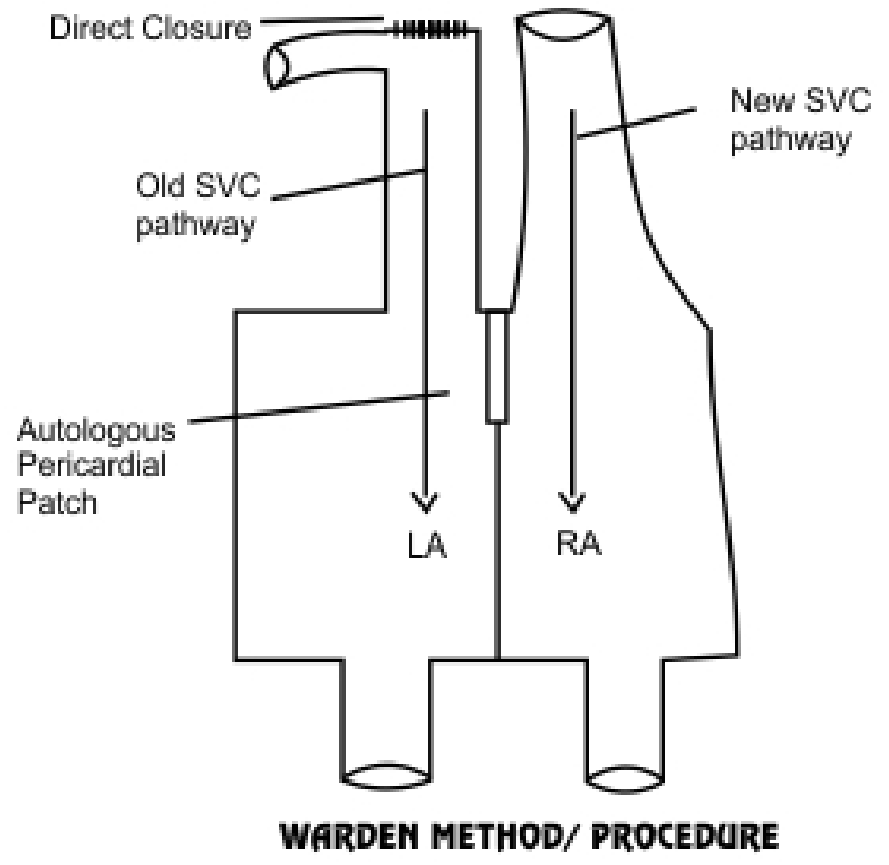




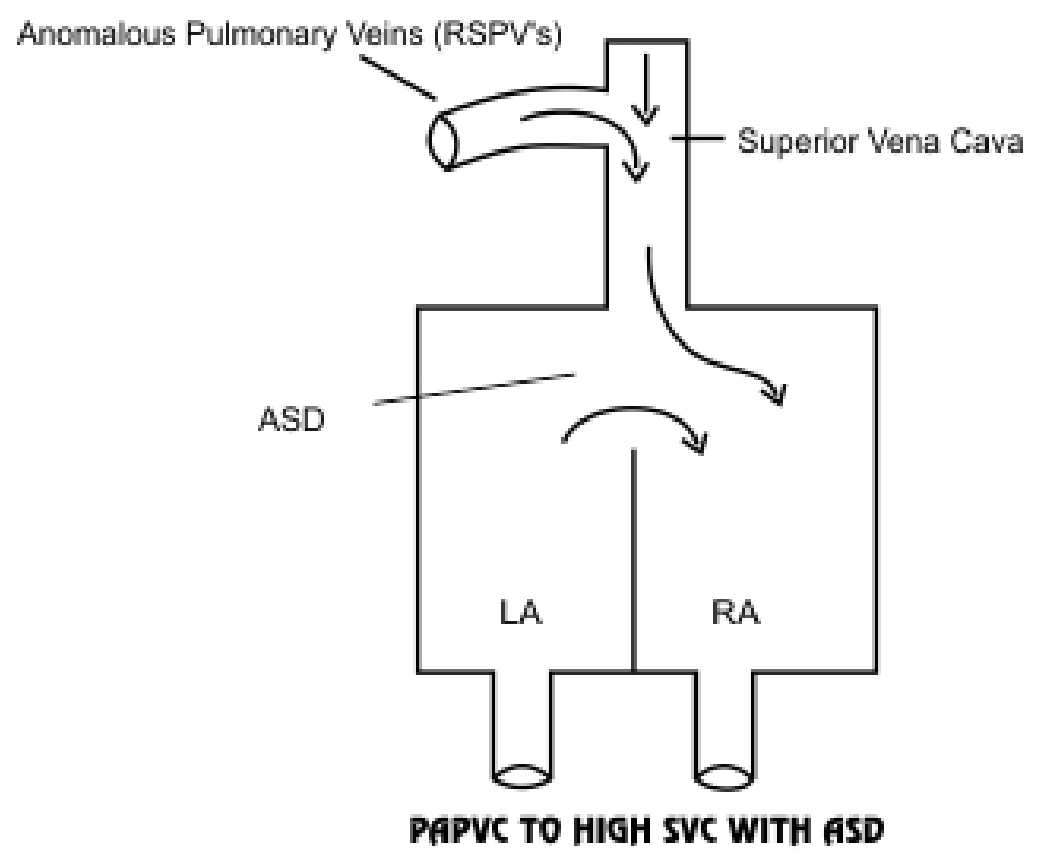

Figure 13 : PAPVC TO HIGH Figure 14 : WARDEN PROCEDURE

SVC WITH ASD

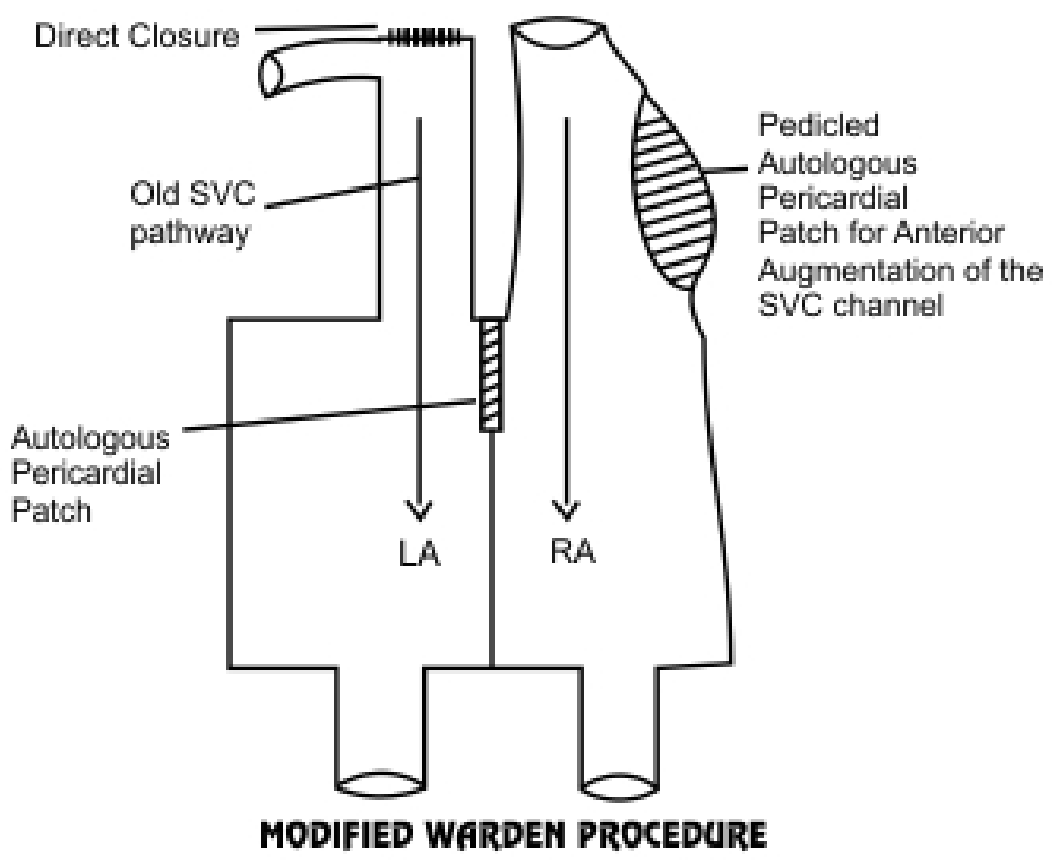

Figure 15 : MODIFIED WARDEN PROCEDURE 
N.B. : RA- Right Atrium, LA- Left Atrium, SVC - Superior Vena Cava, RSPV - Right Superior Pulmonary Vein, ASD - Atrial Septal Defect

(Image Credits, Figure $11-15$ : Dr.Vishal V. Bhende)

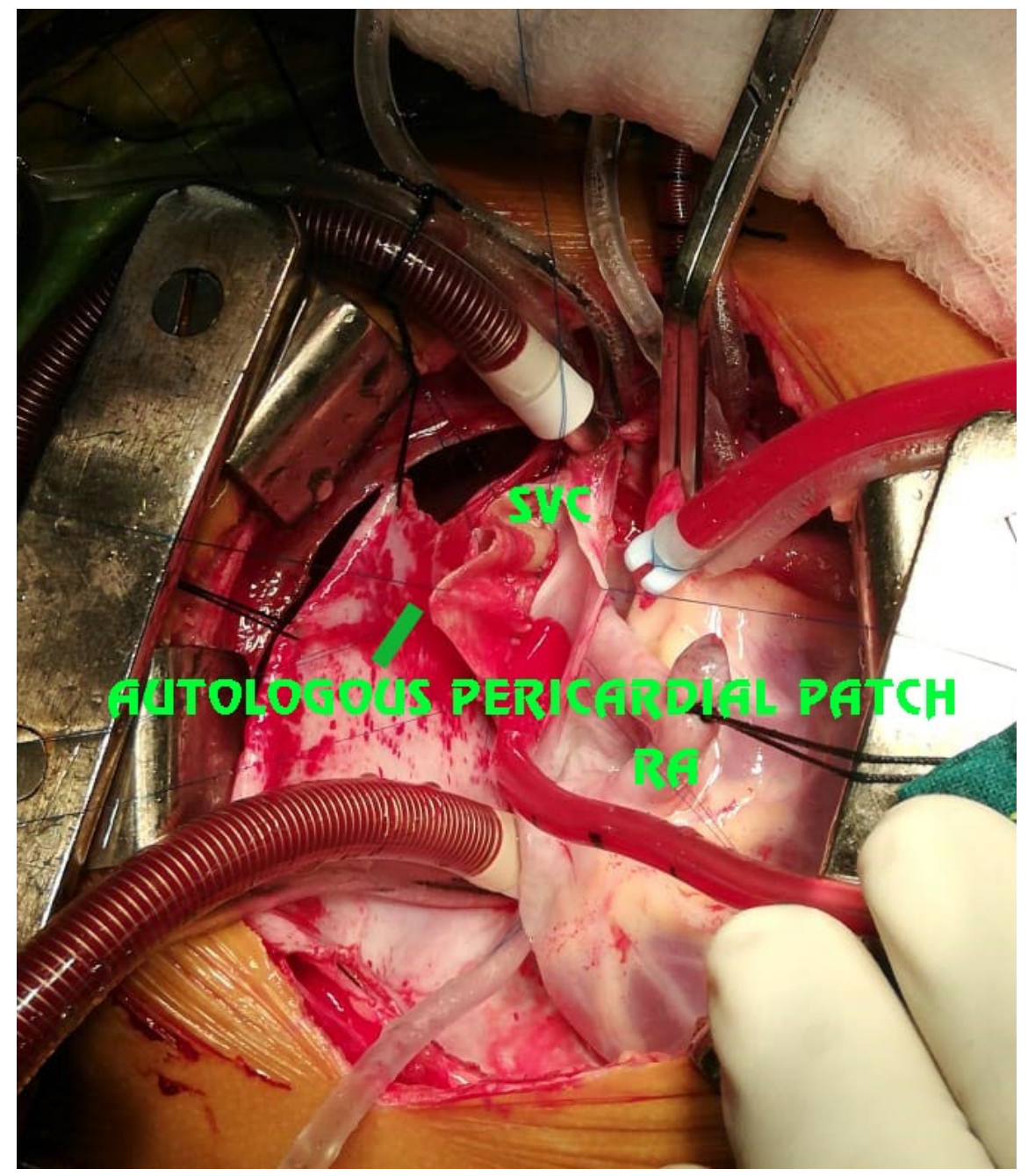




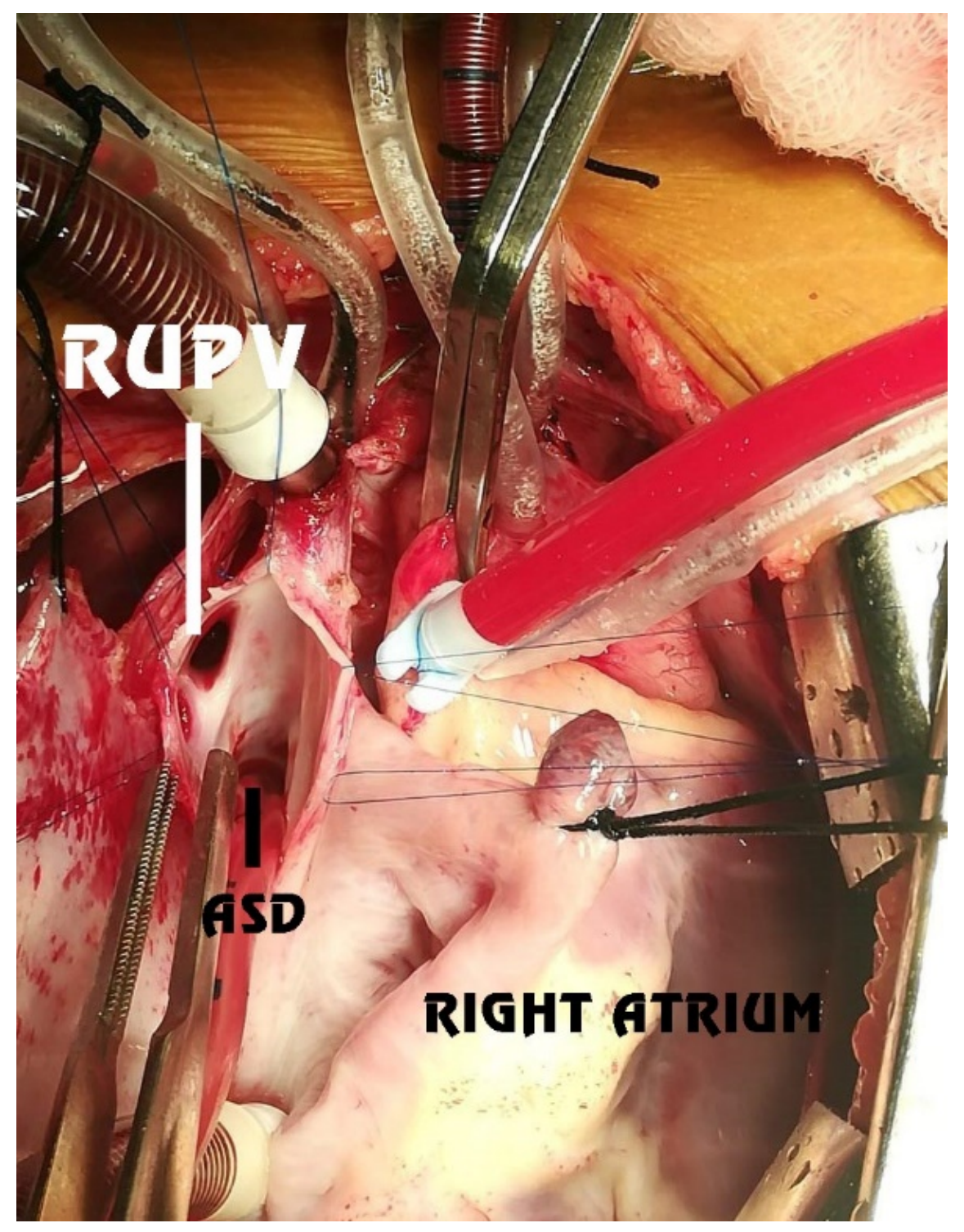

Figure 16 : P 1 SHOWING SV-ASD Figure 17 : SINGLE-PATCH FOR DEFECT P 1 PATIENT 


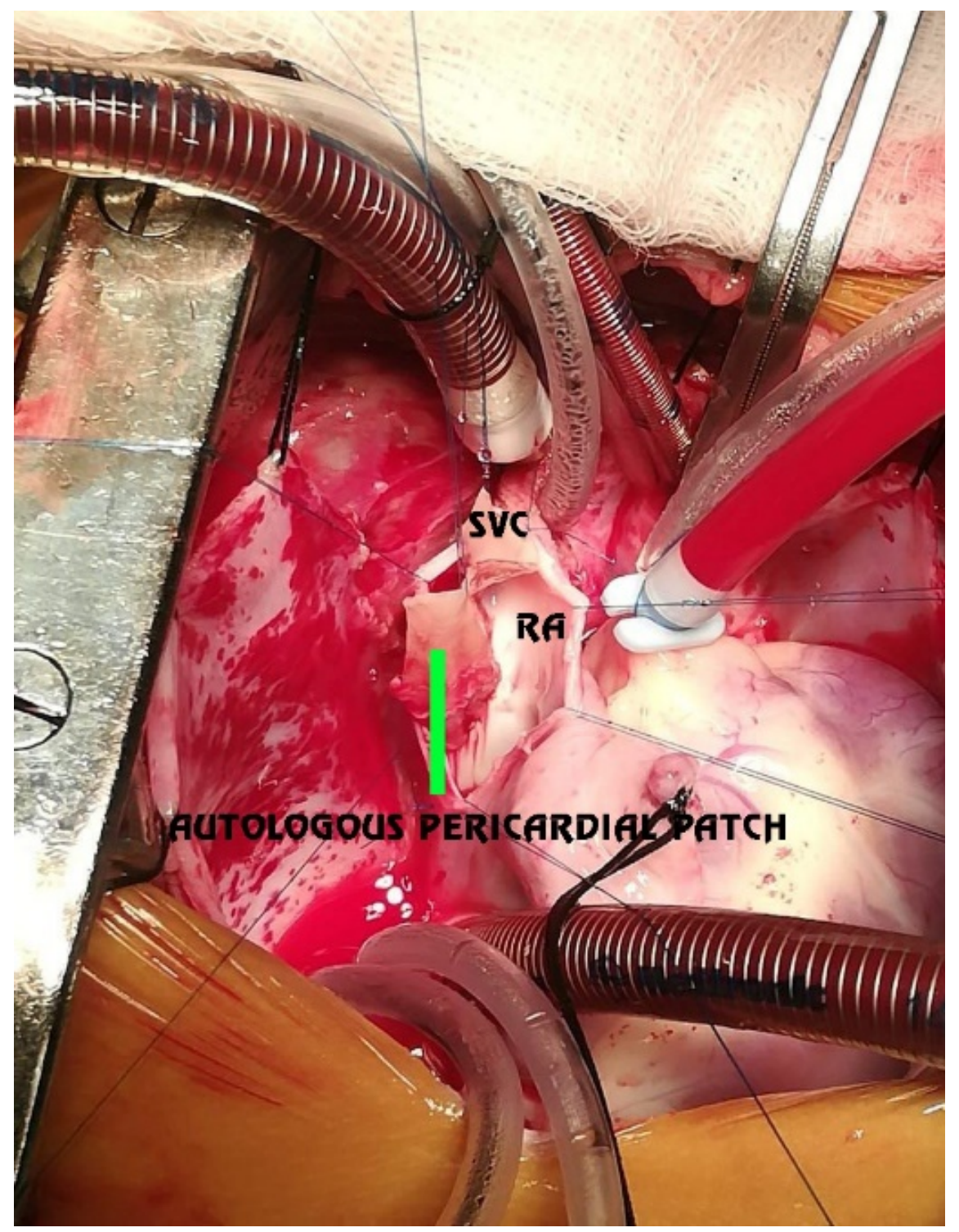




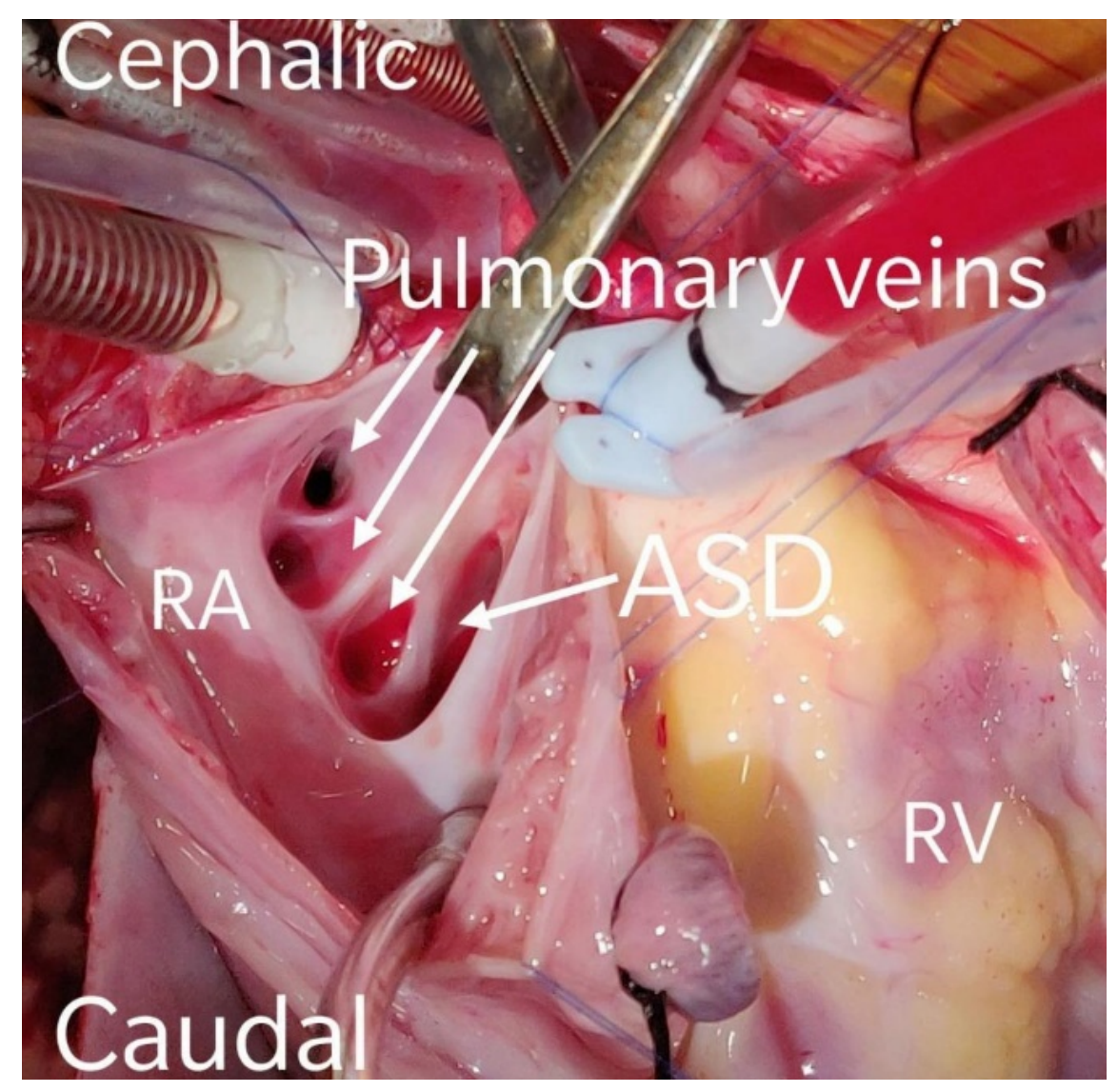

Figure $18:$ SINGLE PATCH FOR Figure $19:$ SV-ASD DEFECT P 2 PATIENT SEEN IN P 7 PATIENT 

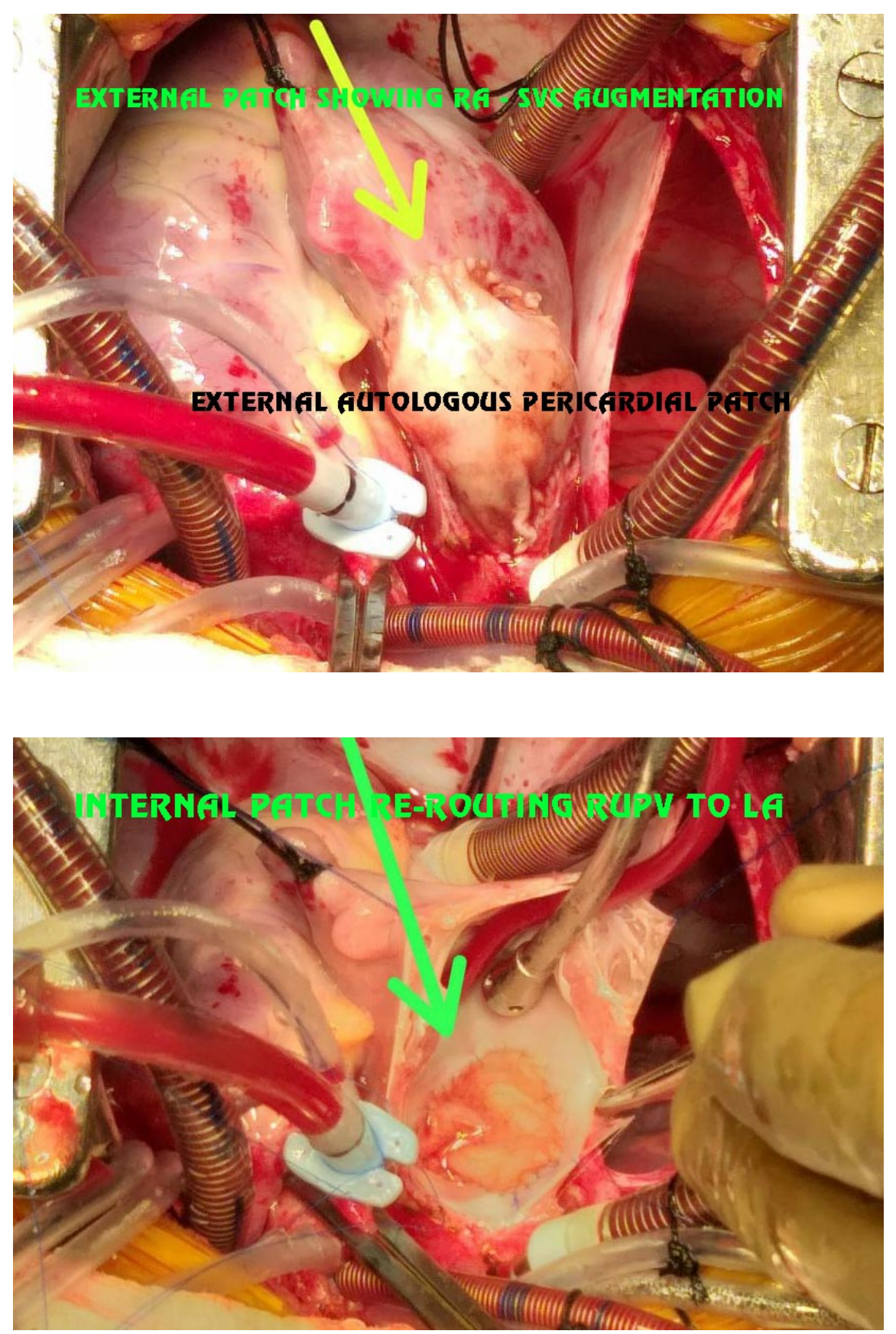

Figure 20 : TWO-PATCH TECHNIQUE Figure 21 : TWO-PATCH

(INTERNAL PATCH) FOR P 9 (EXTERNAL PATCH) TECHNIQUE

PATIENT FOR P 9 PATIENT 


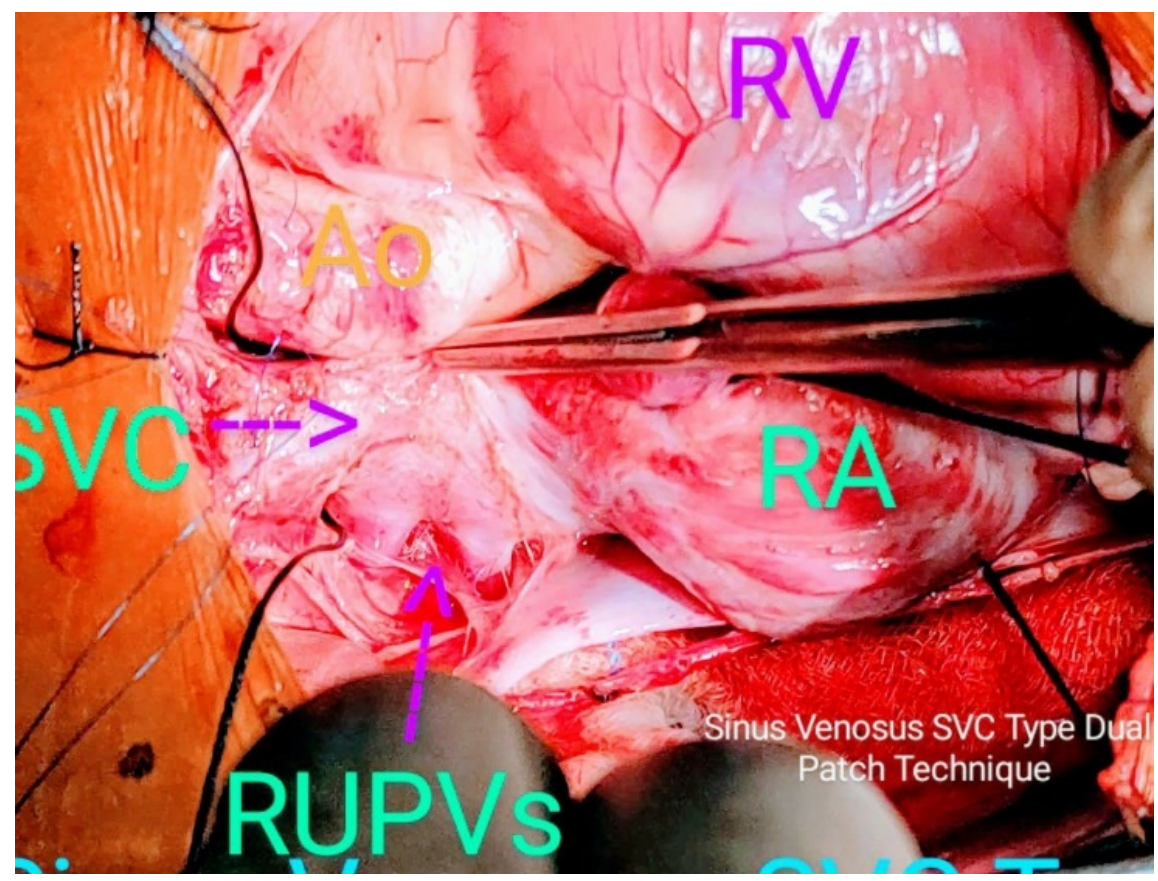

Figure 22 : SV-ASD DEFECT WITH RUPVs FOR P 6 PATIENT

(Image Credits, Figure $16-22$ : Dr.Vishal V. Bhende)

ECG findings

Patients' electrocardiographic patterns were interpreted as normal sinus rhythm, low atrial rhythm, or junctional rhythm by two reviewers who were unaware of the patients' type of surgical repair. Criteria for interpretation as low atrial rhythm included a change in the P-wave axis or a significantly shortened PR interval.

Sinus node dysfunction was defined as persistent sinus bradycardia ( $<50 \mathrm{bpm})$; ectopic atrial rhythm, junctional/nodal rhythm, or a wandering atrial pacemaker $(<60 \mathrm{bpm})$; or pauses of more than 3 seconds. It was also diagnosed on the basis of electrophysiological evidence of sinus node dysfunction. New sinus node dysfunction was defined as sinus node dysfunction that appeared postoperatively (present at hospital dismissal or at a late follow-up) in cases in which sinus rhythm had been present preoperatively.

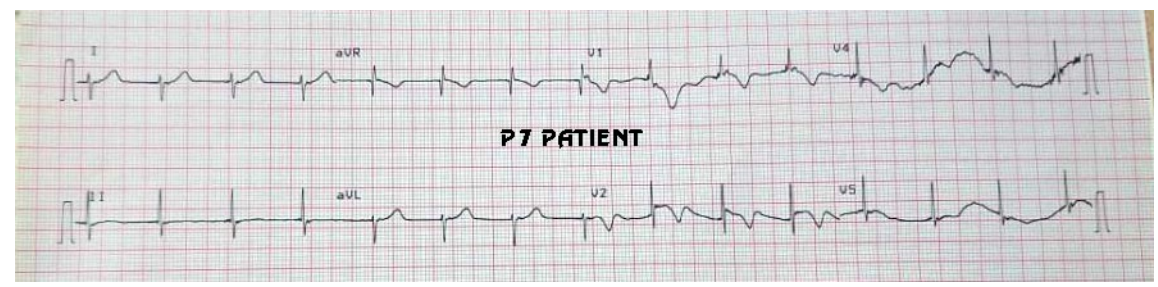




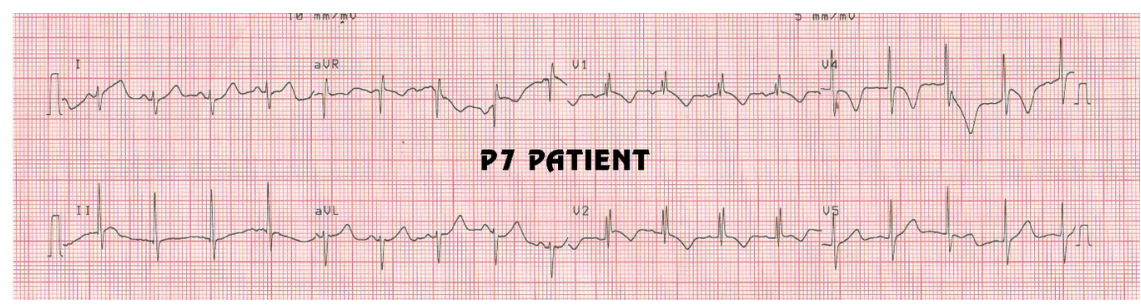

Figure 23 : ECG STRIP OF P 7 PATIENT FROM JUNCTIONAL RHYTHM (ABOVE) TO NORMAL SINUS RHYTHM (BELOW)

Statistical analysis

To perform data analysis, we used statistical software: namely, STATA, version 14.2 (StataCorp. 2015. Stata Statistical Software: Release 14. College Station, TX, USA: StataCorp. LP).

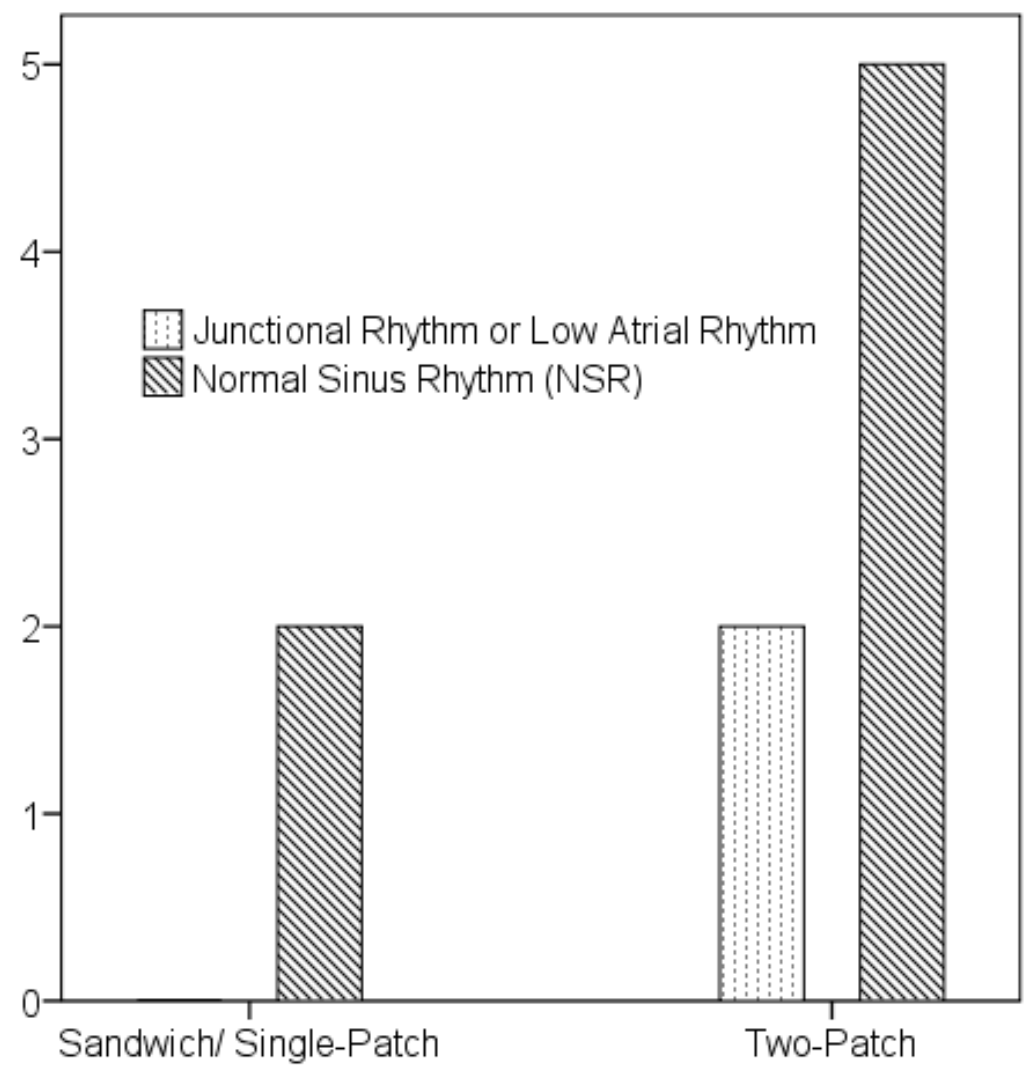

Figure 24 : COMPARISON OF POST- OPERATIVE TO LATE ELECTROCARDIOGRAMS DEMONSTRATING A CHANGE FROM NORMAL SINUS RHYTHM (BLACK BARS) TO A LOW ATRIAL RHYTHM OR JUNCTIONAL RHYTHM (WHITE BARS = SINUS NODE DYSFUNCTION) 


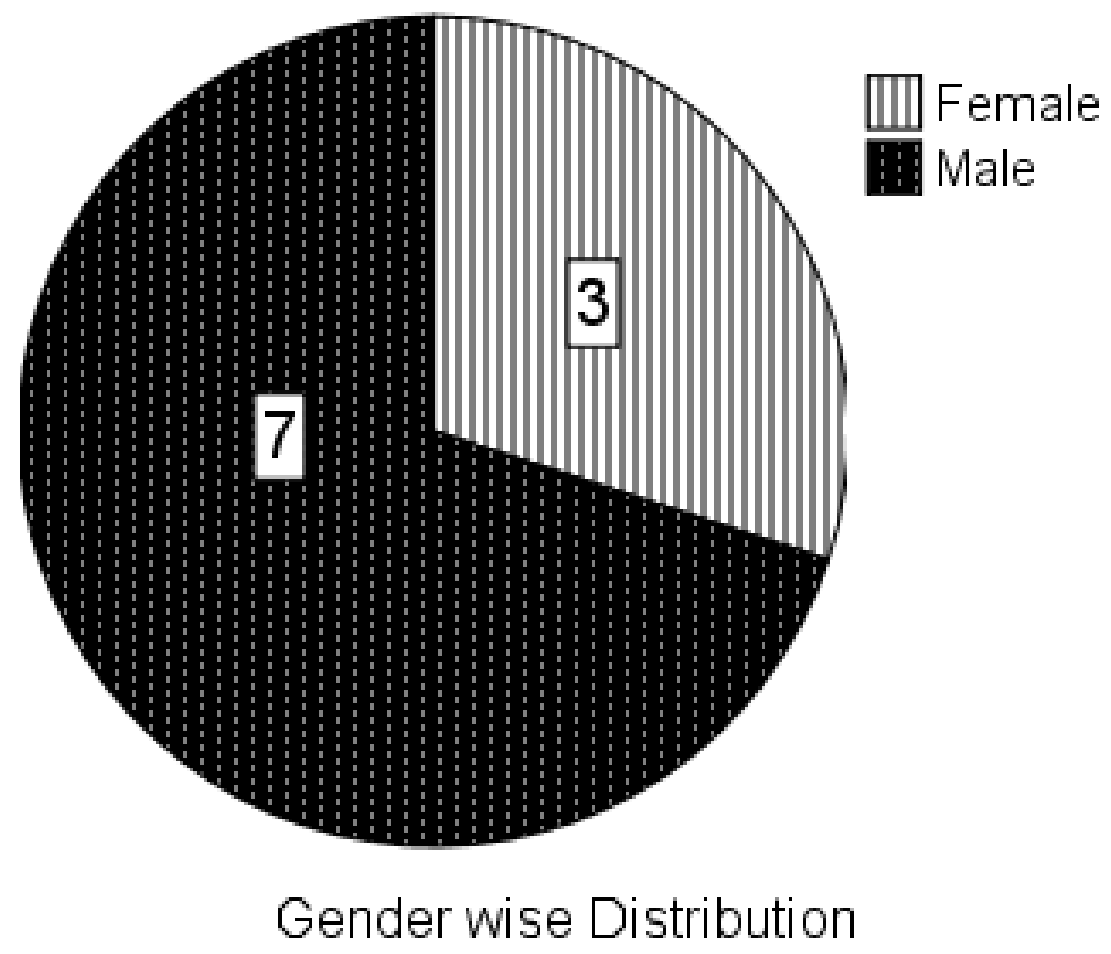

Figure 25: GENDER WISE DISTRIBUTION 


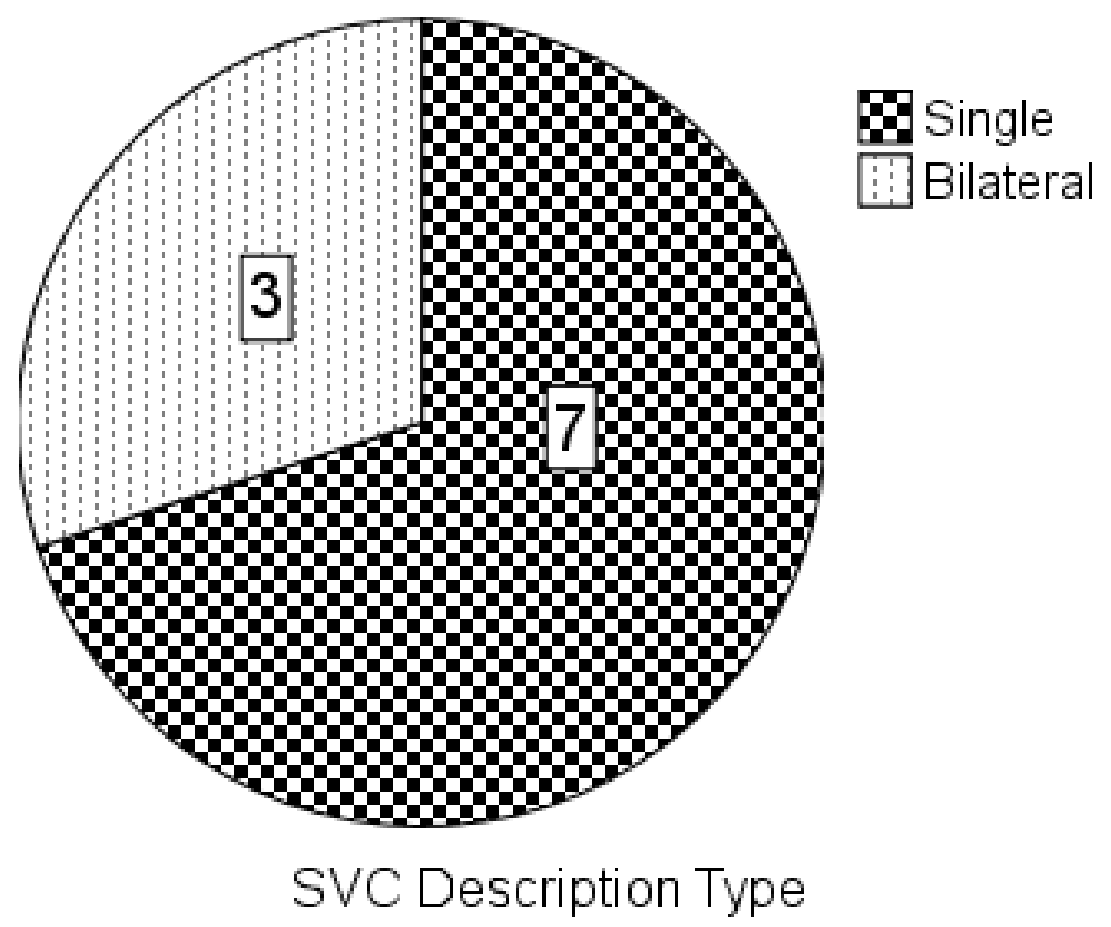

Figure 26 : SVC DESCRIPTION TYPE

\section{Results}

No early or late deaths occurred in this series; no patients required reoperation, and none had residual ASDs. Of the 9 patients with PAPVC involving the RA-SVC junction or RA, none exhibited late stenosis of either the SVC or pulmonary veins on follow-up echocardiography, and none required the Warden procedure. Two patients, P4 and P7, exhibited junctional rhythm on early ECG (Figure 23) and underwent two-patch repair. This junctional rhythm reverted to normal sinus rhythm on late ECG in the hospital. The remaining 8 patients exhibited normal sinus rhythm on early ECG. The association between technique (single- versus two-patch) and rhythm was not significant ( $>$ > 0.999; Figure 24). The gender distribution of patients and type of superior vena cava are illustrated in Figures 25 and 26.)

\section{Discussion}

The repair of SVASD with PAPVC involving the SVC has been a surgical challenge since the earliest reports of this anomaly $[5,6]$. Numerous surgical modifications have been made to repair the defect and redirect pulmonary venous return. Although the early problems of persistent PAPVC and residual ASD have largely been eliminated, problems with SVC stenosis, pulmonary vein stenosis, and sinus node dysfunction remain, as reported in many surgical series. In our study, PAPVC involving the SVC at a low level, the RA, or both was treated by septal transposition [7] or by redirection of the anomalous pulmonary venous flow to the left atrium through the ASD through the use of a patch applied from within the RA [8]. We did not encounter cases in which PAPVC involved the SVC at a high level $(1 \mathrm{~cm}$ or more above the cavoatrial junction) with or without an associated ASD.

In a literature review, we found that use of the two-patch technique was associated with a very low incidence of stenosis of the SVC or pulmonary veins. According to the literature, the incidence of sinus node dysfunction after two-patch repair is significant; this technique entails an incision that crosses the SVC-RA junction, on 
the anterior surface or laterally, which puts the sinus node at risk for damage. DeLeon and associates [8], in a review of 40 patients who underwent repair between 1979 and 1991, found that repair with an RA appendage flap that included a continuous incision through the anterior RA-SVC junction was associated with a higher incidence of sinus node dysfunction than was repair involving either no incision of the SVC or an end-to-side appendage to an SVC anastomosis without any incision near the SVC-RA junction.

Stewart and coworkers [7] studied 15 patients in whom SVASD and PAPVC involving the SVC were repaired with a single-patch technique, which included an incision from the atrial appendage superiorly along the SVC to the level of the PAPVC, thus directly across the sinus node. They noted that $6(40 \%)$ of these patients had early sinus node dysfunction but, of interest, all these postoperative rhythm problems resolved before hospital discharge. In one of our patients (P9), early sinus node dysfunction returned to normal sinus rhythm.

All 7 patients who underwent two-patch repair continue to be monitored at our cardiac center. Two patients exhibited junctional rhythm on ECG early in the postoperative period, but this later reverted to normal sinus rhythm. The remaining 5 patients exhibited normal sinus rhythm on early ECG.

Because patients who underwent two-patch repair continued to exhibit normal sinus rhythm on late ECG with no turbulence in the SVC-RA junction pathway and with no arrhythmias, we advocate two-patch repair over single-patch repair.

According to our review of the literature, the Warden procedure involves no incisions near the sinus node or the sinus nodal artery, and no sinus node dysfunction has occurred after this procedure. Gustafson et al. and Warden et al. have reported on their growing series of patients; the initial patient underwent surgery in $1967[9,10]$. As of the most recent report, they had performed the Warden procedure in 40 patients, of whom only 1 (2.5\%) exhibited continuing sinus node dysfunction [10]. Two other patients exhibited early sinus node dysfunction, but normal sinus rhythm was achieved by 5 days and 6 months after surgery.

Shahriari and colleagues [11] reported the results of SVASD repair in 54 patients, of whom 27 underwent single-patch repair, 12 underwent two-patch repair, and 13 underwent the Warden procedure. The rate of arrhythmias in the entire series was very low; $100 \%$ of the patients who underwent the Warden procedure remained in normal sinus rhythm. Similarly, Gaynor and colleagues [12] reported on a series of 11 patients who underwent the Warden procedure between 1987 and 1995, none of whom exhibited sinus node dysfunction. DiBardino and associates [13] reported a single case of transient sinus bradycardia among 16 patients who underwent the Warden procedure between 1995 and 2004 [14]. In summary, the literature indicates that the Warden procedure essentially eliminates the possibility of sinus node injury and thus sinus node dysfunction.

In the 2 patients who underwent single-patch repair, turbulence was noted in the SVC-RA junction pathway: Patient P1 exhibited a peak pressure of $4 \mathrm{~mm} \mathrm{Hg}$ (mean, $2 \mathrm{~mm} \mathrm{Hg}$ ), and P2 exhibited a peak pressure of $18 \mathrm{~mm} \mathrm{Hg}$ (mean, $18 \mathrm{~mm} \mathrm{Hg}$ ). No rhythm abnormalities occurred after single-patch repair [15,16].

In our series, patient P10 had left-sided isolated PAPVC with ASD and pulmonary stenosis. In this patient, we rerouted the PAPVC by creating an anastomosis between the left atrial appendage and the vertical vein with flush ligation of the vertical vein and the innominate vein, leaving the hemiazygos vein in the systemic pathway. We used a glutaraldehyde-treated pericardial patch to close the ASD and performed pulmonary valvotomy.

Patient P4 underwent preoperative evaluation with dynamic cardiac CT because intracranial arteriovenous malformations were suspected of causing dilatation of the SVC.

In the combined series reported by Shariari et al., Gaynor et al., and DiBardino et al., no patients had SVC stenosis, and only 2 had pulmonary vein stenosis. Of interest is that in both patients, who were treated at different hospitals, pulmonary vein stenosis appeared to result from untreated shrinkage of an autologous pericardial patch. The authors recommended using a polytetrafluoroethylene intra-atrial baffle. In our series, we used pericardium patches without any evidence of pulmonary vein stenosis caused by patch shrinkage. 


\section{Limitations}

A limitation of this study was its retrospective design. Because the natural history of SVASD is not assessable, and because no historical control group is available for comparison, the natural history of unoperated SVASD is unknown; however, it is probably similar to that of large ASDs.

The presence of atrial arrhythmias decreases the ability to detect sinus node dysfunction; thus the frequency of sinus node dysfunction detection may have been underestimated.

\section{Conclusions}

The decision to surgically repair SVASD should be individualized. However, such intervention is rarely necessary or advisable in an infant younger than 1 year or in very elderly patients. Our findings confirm that the two-patch technique remains the procedure of choice for patients with a SVASD and PAPVC involving the RA or the SVC-RA junction. In cases of bilateral SVC without innominate vein connection, single-patch repair can be attempted without causing much turbulence in the SVC-RA junction, in comparison with cases of single SVC.

The Warden procedure should be an option in pediatric cases of SVASD with PAPVC involving high levels of the SVC because it provides unobstructed drainage of the SVC and pulmonary veins and virtually eliminates the problem of sinus node dysfunction that is common with the two-patch repair.

Despite the complexity of the lesion, repair of SVASD with associated APVC is associated with low rates of morbidity and mortality, even in patients older than 40 years. Survival rates are similar to those of a matched population, and although repair is suggested as early as possible, it should be considered whenever repair may affect survival or symptoms .

\section{ACKNOWLEDGEMENTS -}

We are thankful to -

1. Mrs. Mamta Roshan Patel, Bio- Statistician, Central Research services, Bhaikaka University, Karamsad.Email : mamtarp@charutarhealth.org

2. Mr. Naresh Jayantibhai Fumakiya, Echo-Cardiographer, Bhanubhai and Madhuben Patel Cardiac Centre, Shree Krishna Hospital, Karamsad.

3. Mr. Khushal N. Vankar, Office Assistant, Department of Diagnostic Services, Shree Krishna Hospital, Bhaikaka University, Karamsad.Email : khushalnv@charutarhealth.org

\section{References}

1. Peacock TB: Malformations of the heart. In: Peacock TB, ed. On Malformations, \&c., of the Human Heart: With Original Cases. London, UK: John Churchill. 1858:11-102. 10.1017/S1047951100010349

2. Oliver JM, Gallego P, Gonzalez A, Dominguez FJ, Aroca A, Mesa JM: Sinus venosus syndrome: atrial septal defect or anomalous venous conection? A multiplane transoesophageal approach. Heart. 2002, 88:634-638. 10.1136/heart.88.6.634

3. Van Praagh S, Carrera ME, Sanders SP, Mayer JE, Van Praagh R: Sinus venosus defects: unroofing of the right pulmonary veins: anatomic and echocardiographic findings and surgical treatment. Am Heart J. 1994, 128:365-379. 10.1016/0002-8703(94)90491-X

4. Kirklin JW, Barratt-Boyes BG, eds: Cardiac Surgery: Morphology, Diagnostic Criteria, Natural History, Techniques, Results, and IndicationsNew York. NY: Churchill Livingstone; 1993. 1:609-644.

5. Schuster SR, Gross RE, Colodny AH: Surgical management of anomalous right pulmonary venous drainage to the superior vena cava, associated with superior marginal defect of the atrial septum. Surgery. 1962, 51:805-8. 10.5555/uri:pii:0039606062903252

6. Kyger ER III, Frazier H, Cooley DA, et al.: Sinus venosus atrial septal defect: early and late results following closure in 109 patients. Ann Thorac Surg. 1978, 25:44-50. 10.1016/S0003-4975(10)63485-6 
7. Stewart S, Alexson C, Manning J: Early and late results of repair of partial anomalous pulmonary venous connection to the superior vena cava with a pericardial baffle. Ann Thorac Surg. 1986, 41:498501. 10.1016/S0003-4975(10)63026-3

8. DeLeon SY, Freeman JE, Ilbawi MN, et al.: Surgical techniques in partial anomalous pulmonary veins to the superior vena cava. Ann Thorac Surg. 1993, 55:1222-6. 10.1016/0003-4975(93)90038-J

9. Gustafson RA, Warden HE, Murray GF, Hill RC, Rozar GE: Partial anomalous pulmonary venous connection to the right side of the heart. J Thorac Cardiovasc Surg. 1989, 98:861-8. 10.1016/S00225223(19)34264-3

10. Gustafson RA, Warden HE, Murray GF: Partial anomalous pulmonary venous connection to the superior vena cava. Ann Thorac Surg. 1995, 60:5614-7. 10.1016/j.ejcts.2011.05.043

11. Shahriari A, Rodefeld MD, Turrentine MW, Brown JW: Caval division technique for sinus venosus atrial septal defect with partial anomalous pulmonary venous connection. Ann Thorac Surg. 2006, 81:224-30. 10.1016/j.athoracsur.2005.07.015

12. Gaynor JW, Burch M, Dollery C, Sullivan ID, Deanfield JE, Elliott MJ: Repair of anomalous pulmonary venous connection to the superior vena cava. Ann Thorac Surg. 1995, 59:1471-5. 10.1016/00034975(95)00150-J

13. DiBardino DJ, McKenzie ED, Heinle JS, Su JT, Fraser CD Jr: The Warden procedure for partially anomalous pulmonary venous connection to the superior caval vein. Cardiol Young. 2004, 14:64-7. $10.1017 /$ S1047951104001118

14. Warden HE, Gustafson RA, Tarnay TJ, Neal WA: An alternative method for repair of partial anomalous pulmonary venous connection to the superior vena cava. Ann Thorac Surg. 1984, 38:601-5. 10.1016/S0003-4975(10)62317-X

15. Jost CH, Connolly HM, Danielson GK, et al.: Sinus venosus atrial septal defect. long-term postoperative outcome for 115 patients. Circulation. 2005, 112:1953-1958. 10.1161/CIRCULATIONAHA.104.493775

16. Stewart RD, Bailliard F, Kelle AM, Backer CL, Young L, Mavroudis C: Evolving Surgical Strategy for Sinus Venosus Atrial Septal Defect: Effect on Sinus Node Function and Late Venous Obstruction. Ann Thorac Surg. 2007, 84:1651-5. 10.1016/j.athoracsur.2007.04.130

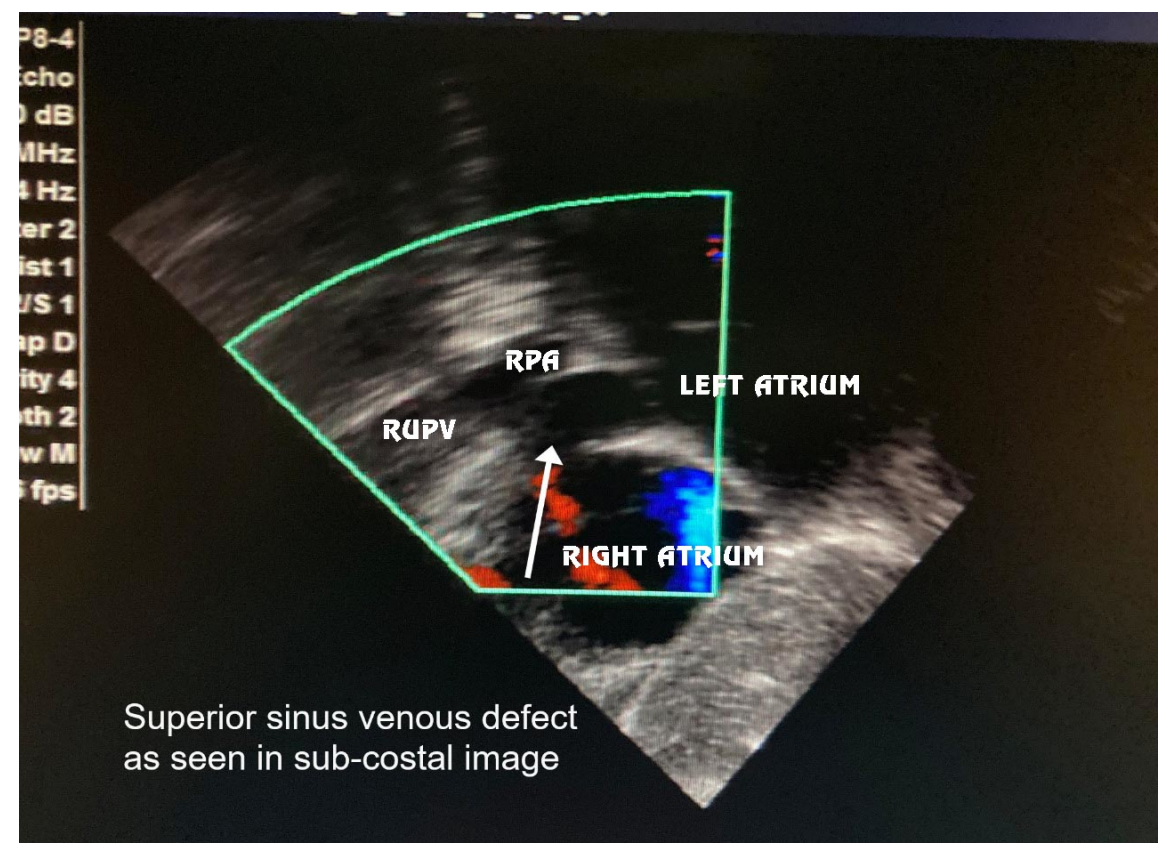



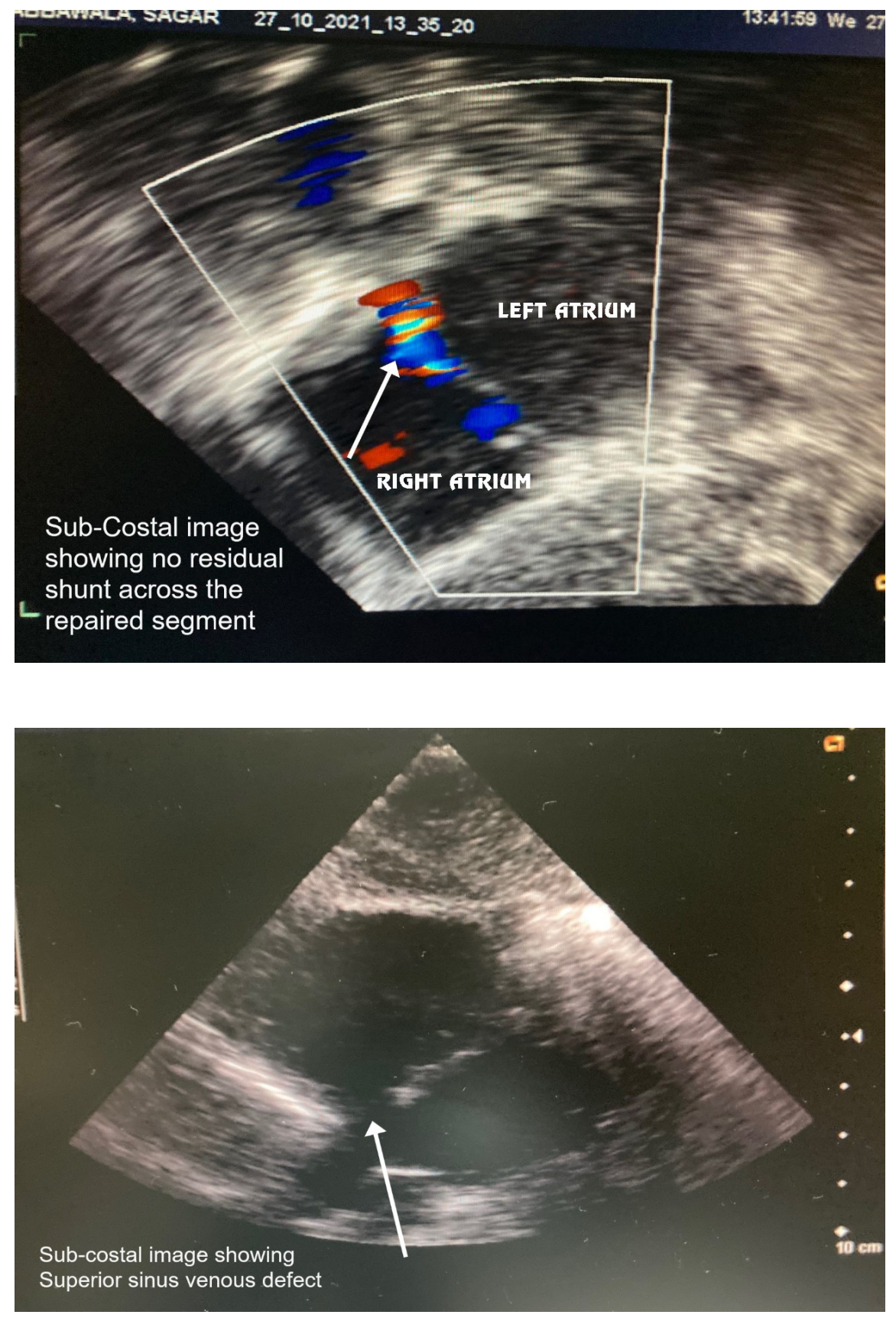

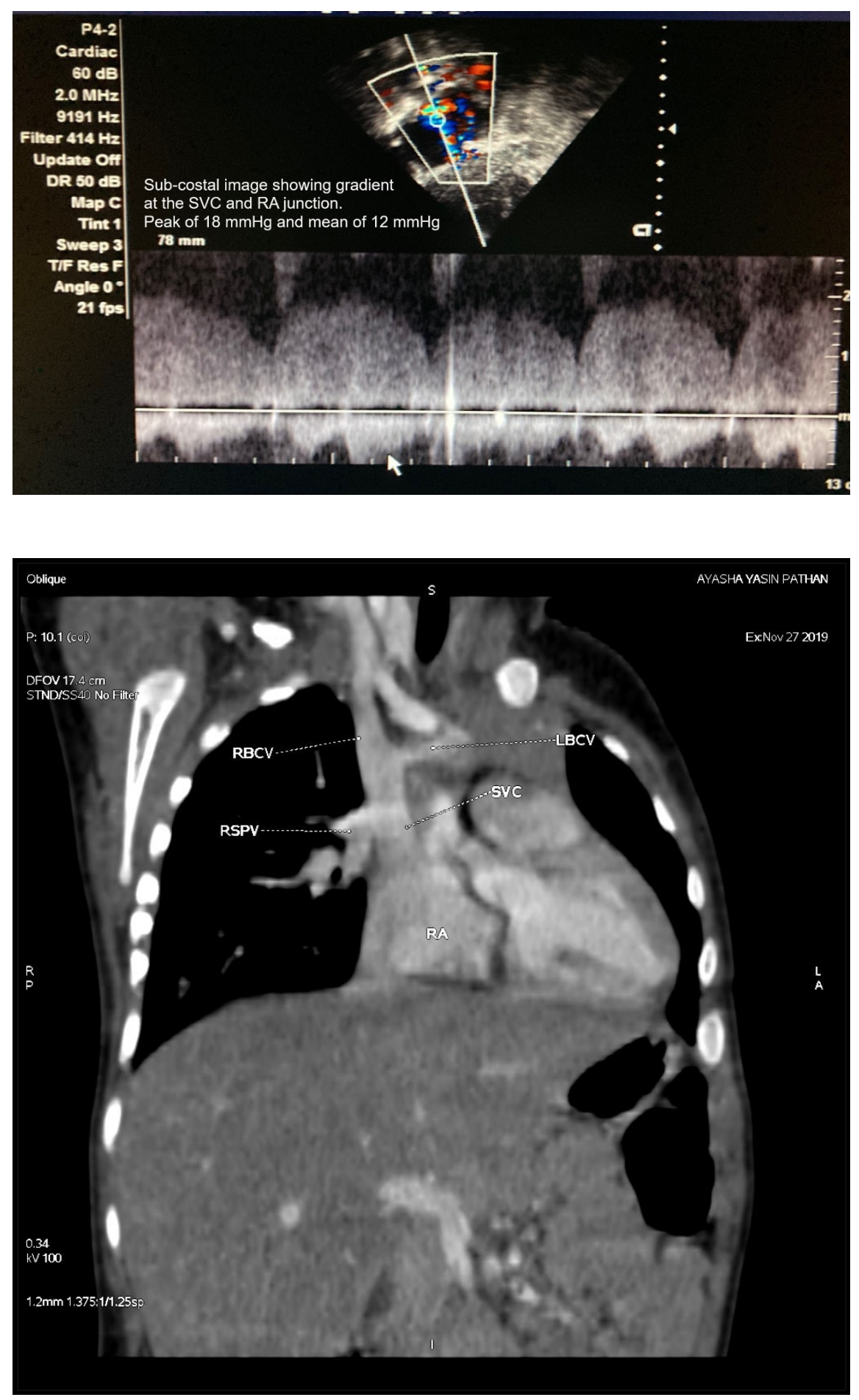


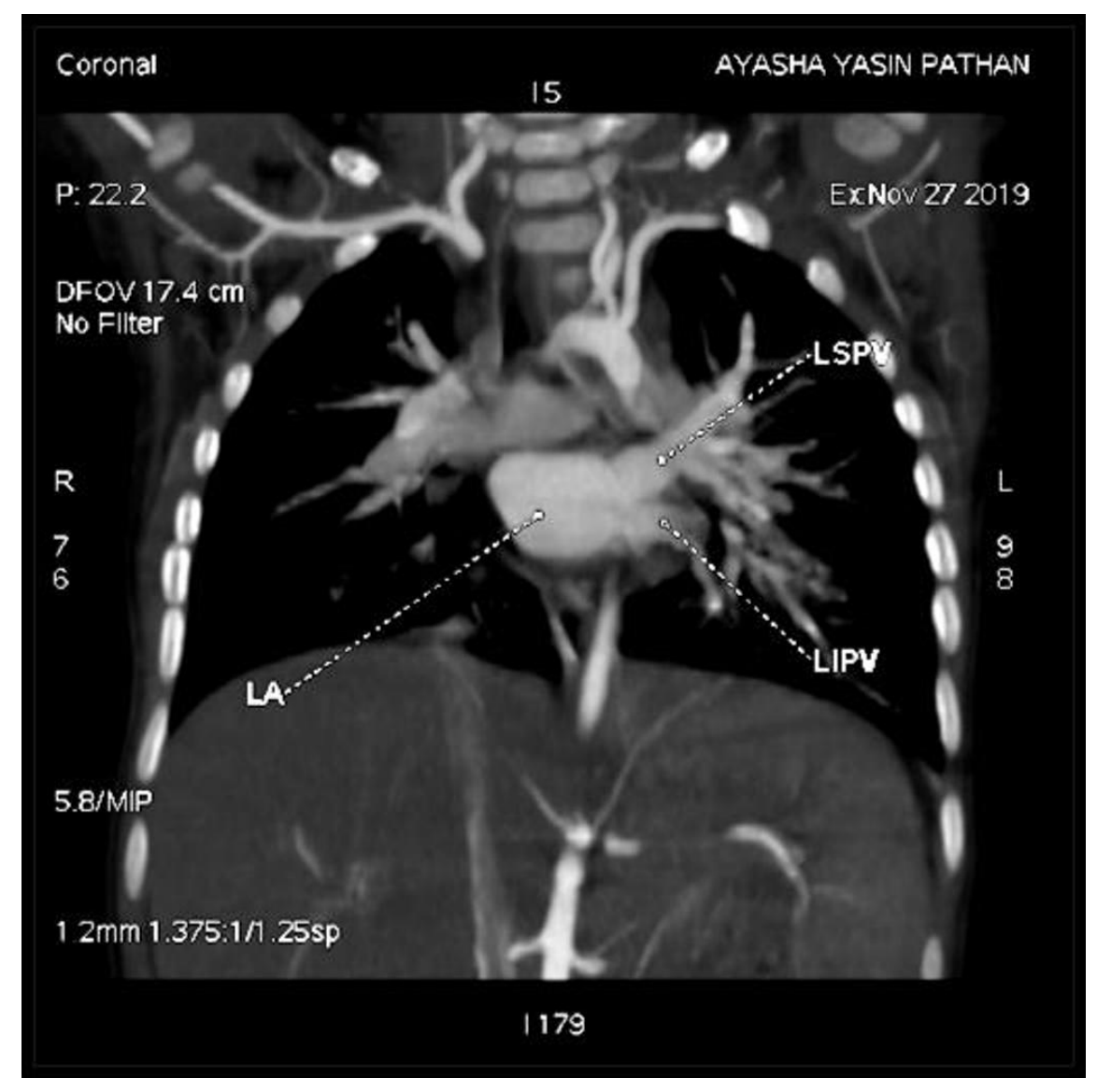




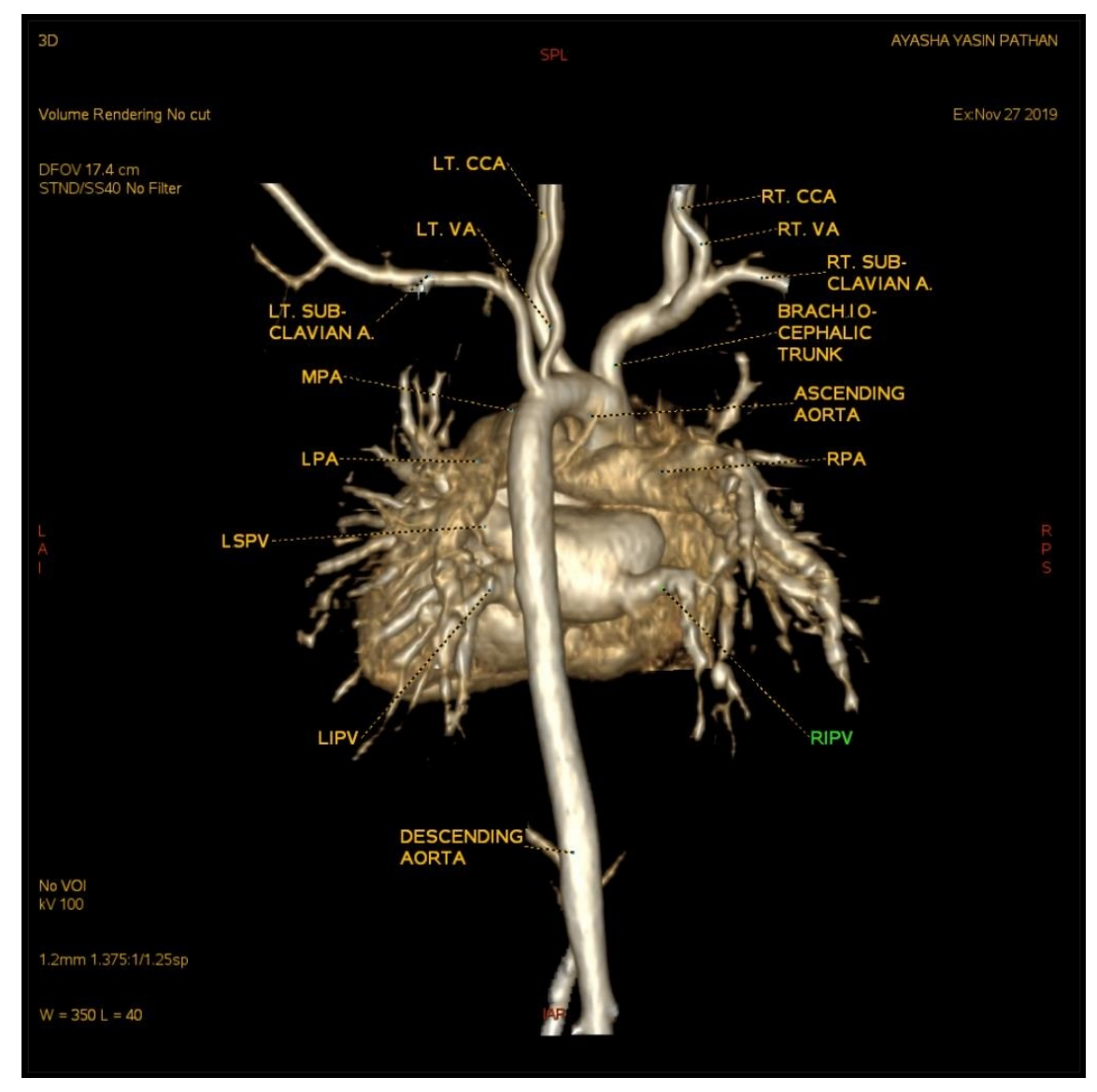




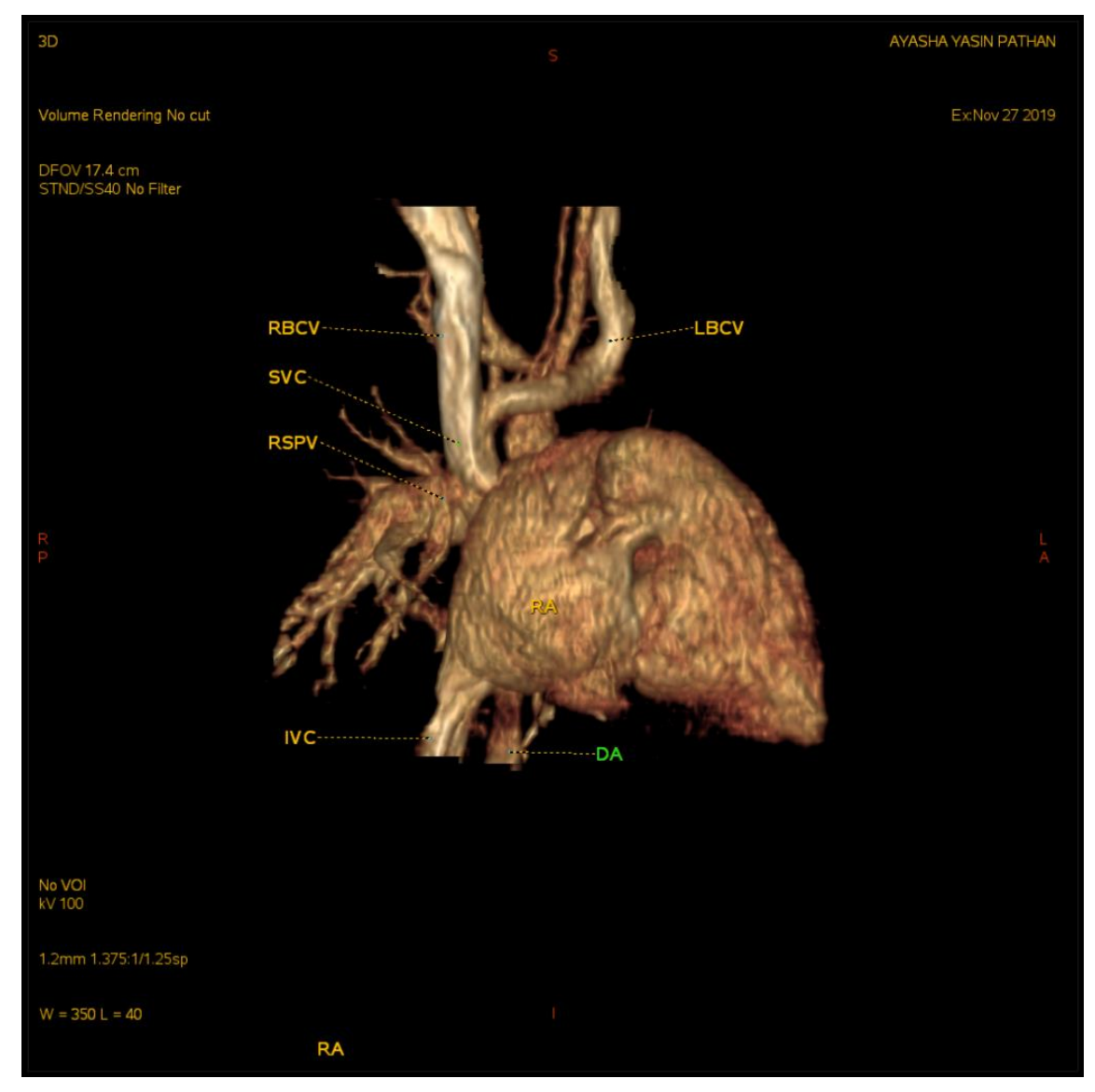




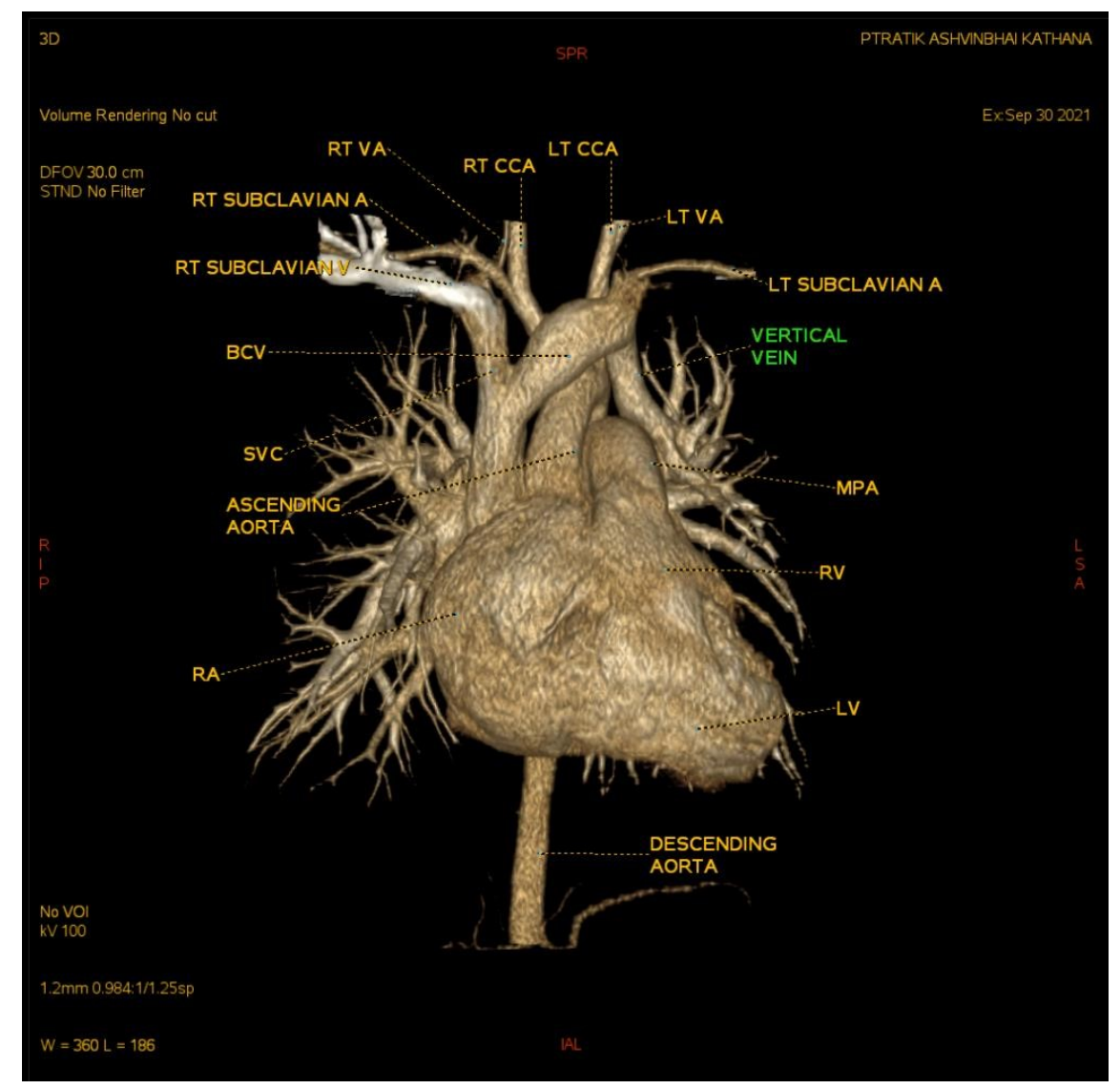




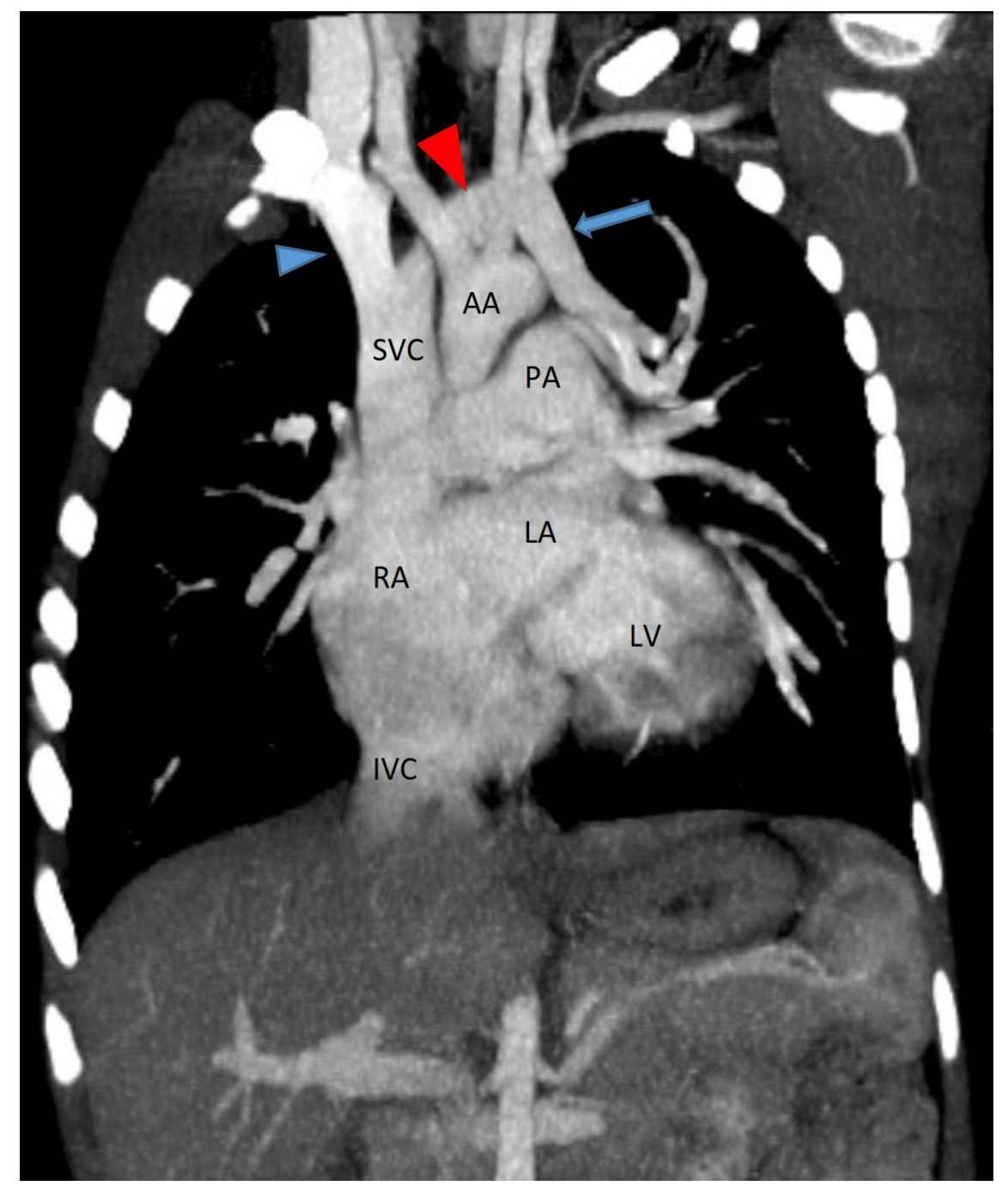




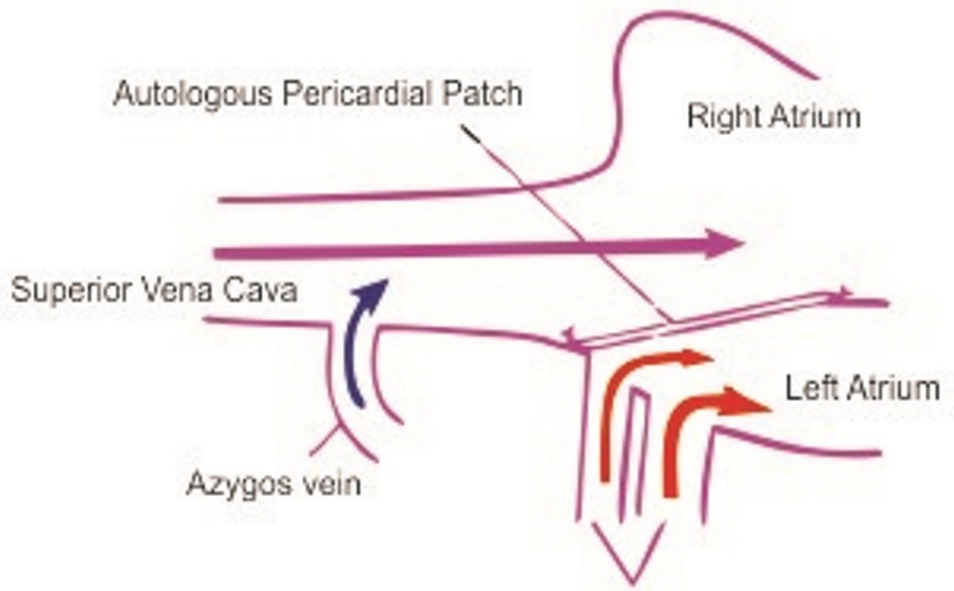

Anomalous RSPV's

SINGLE-PATCH / SANDWICH TECHNIQUE

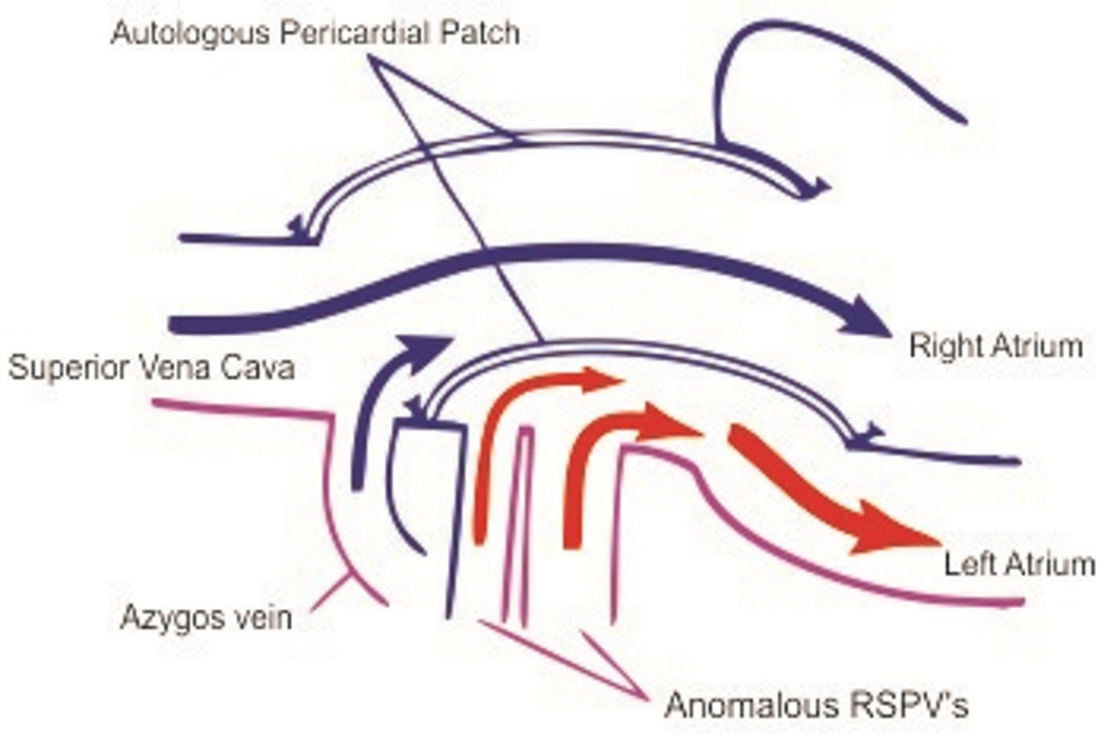

TWO-PATCH TECHNIQUE 

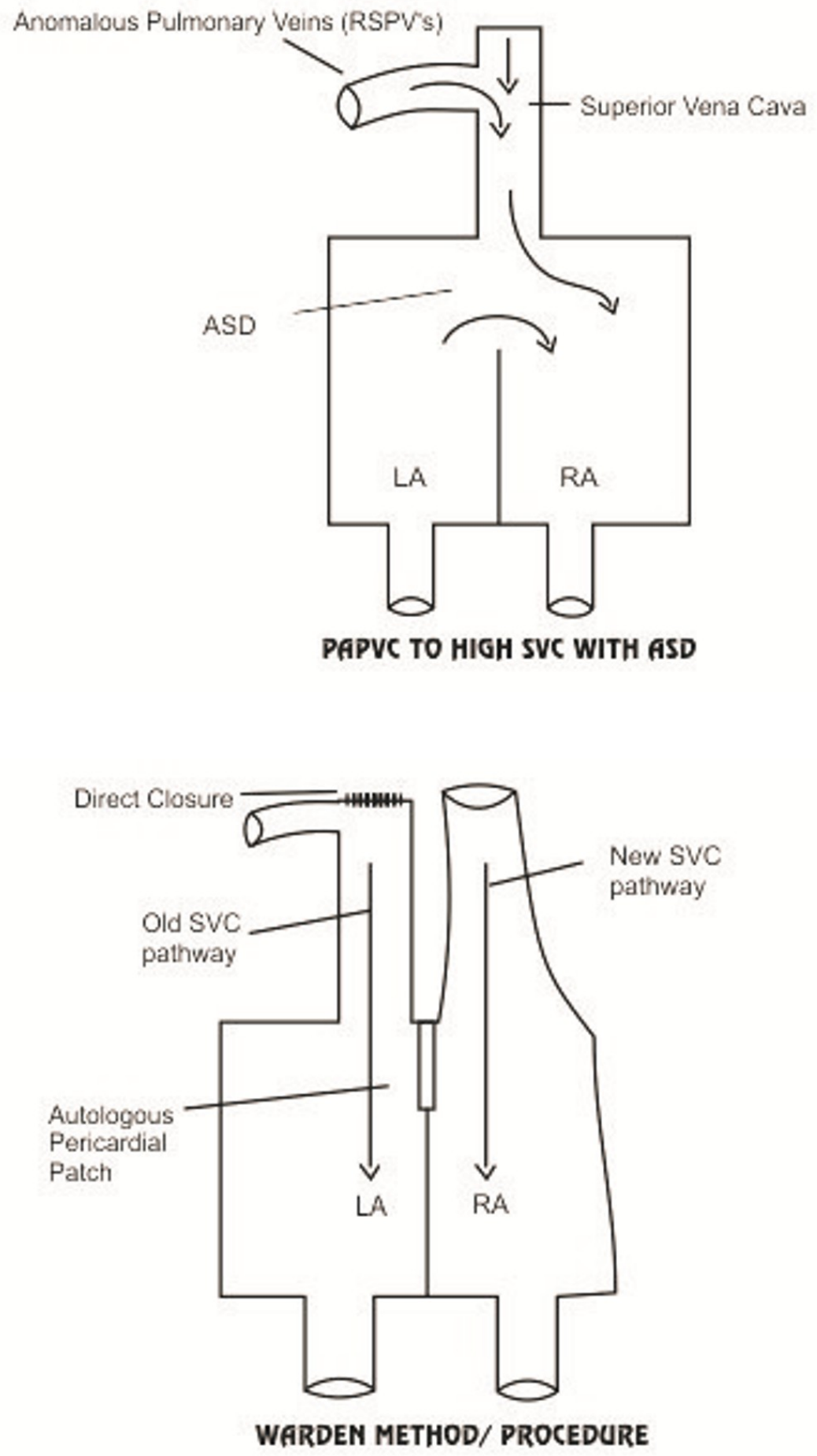


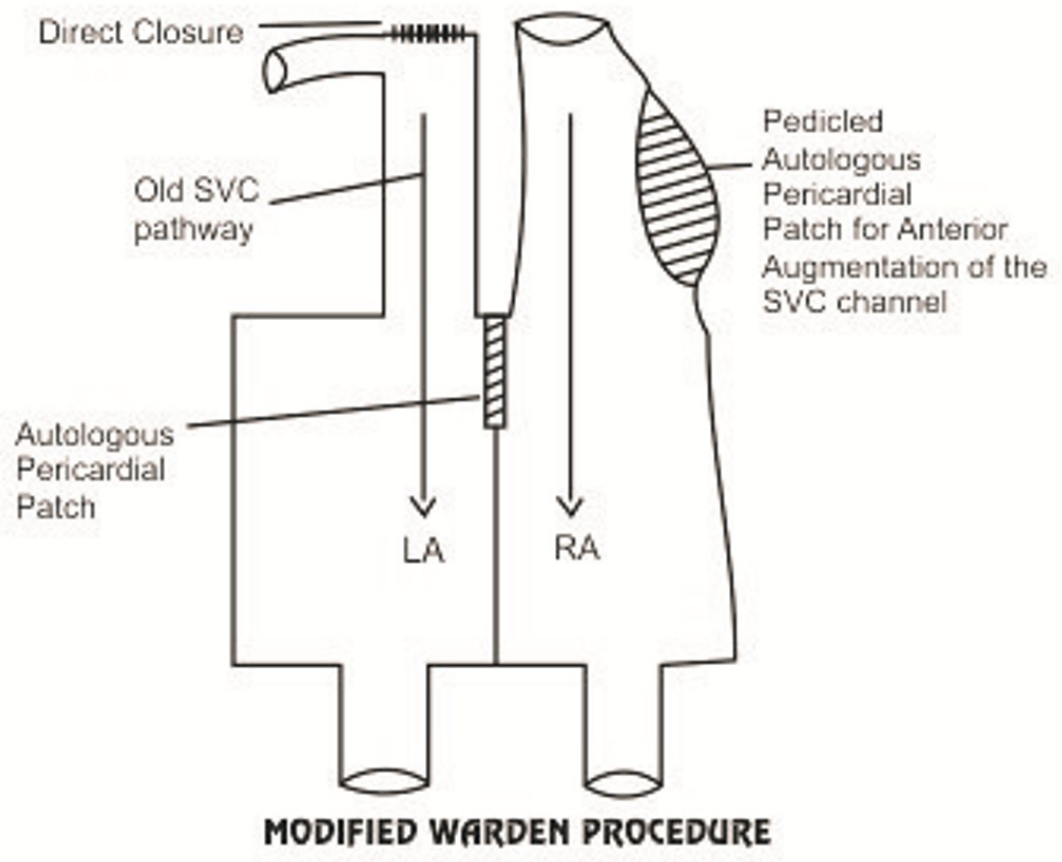




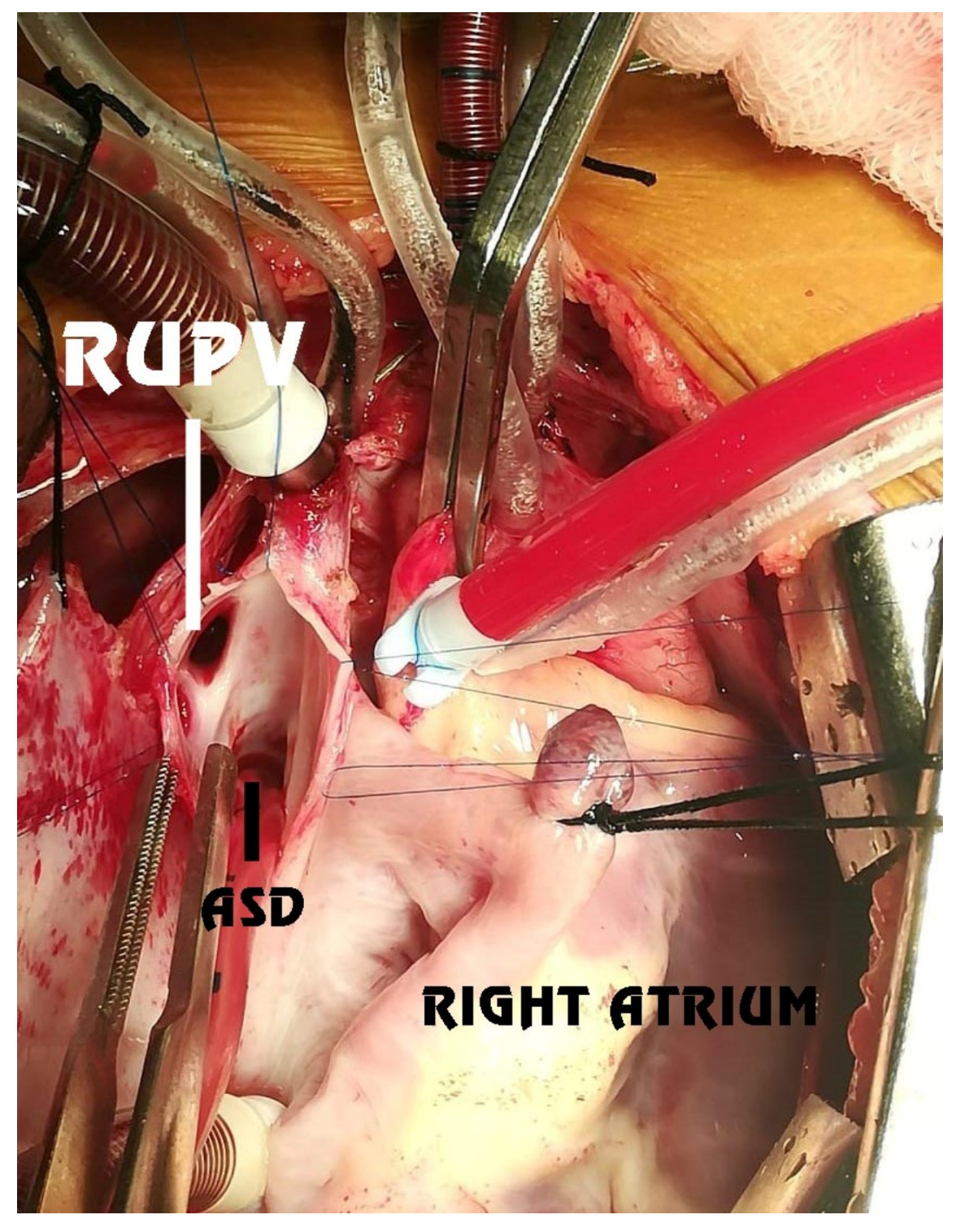




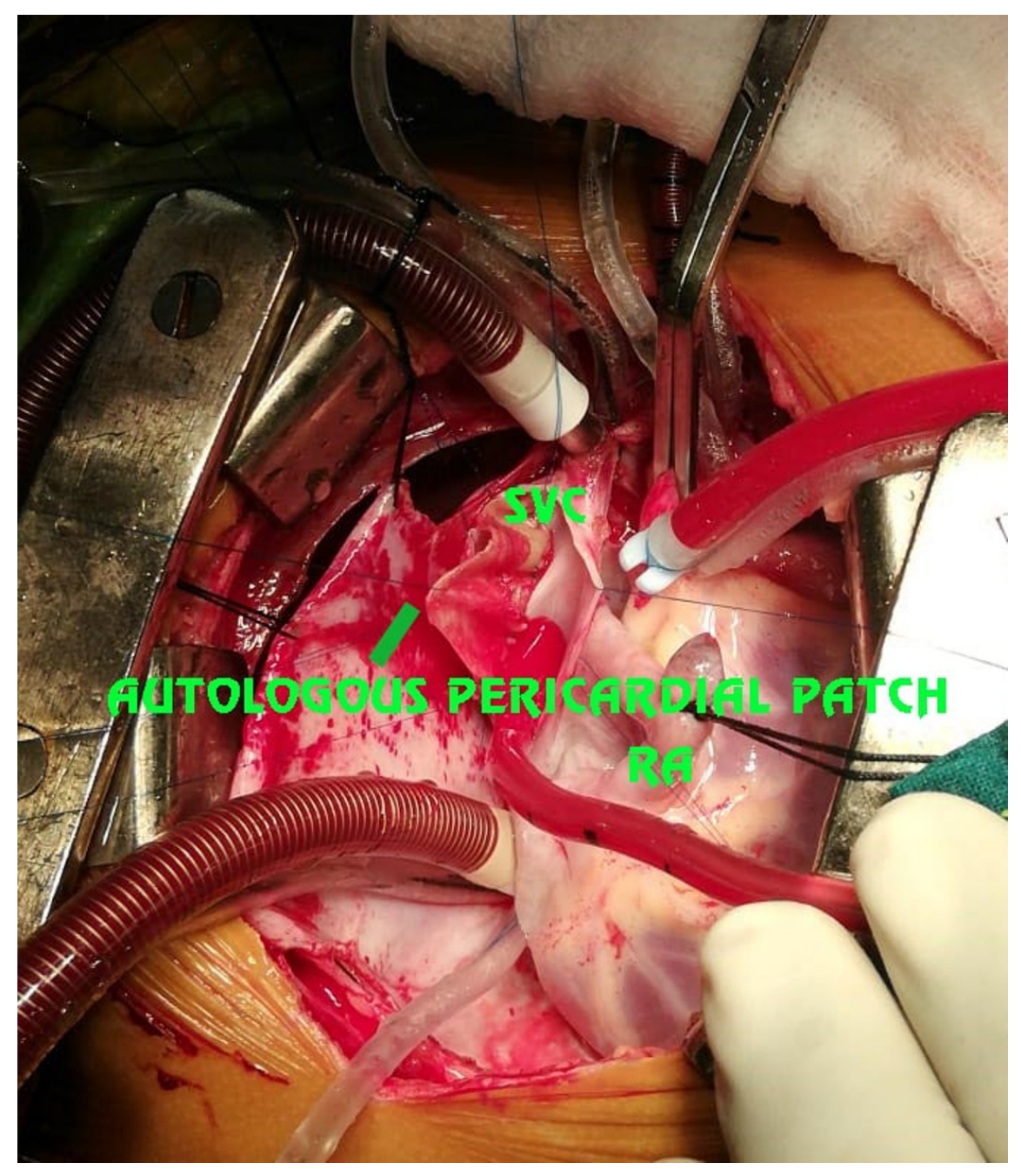




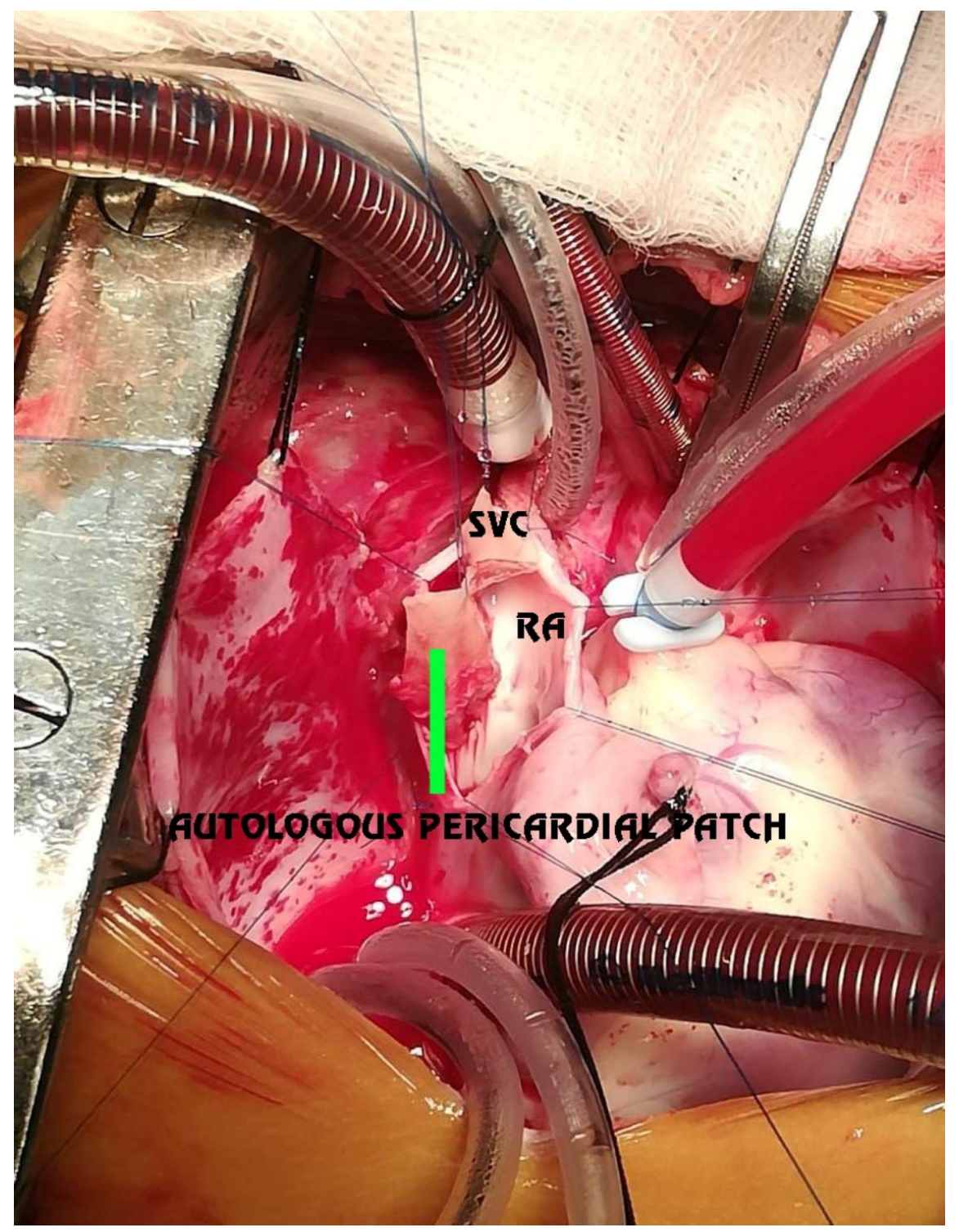



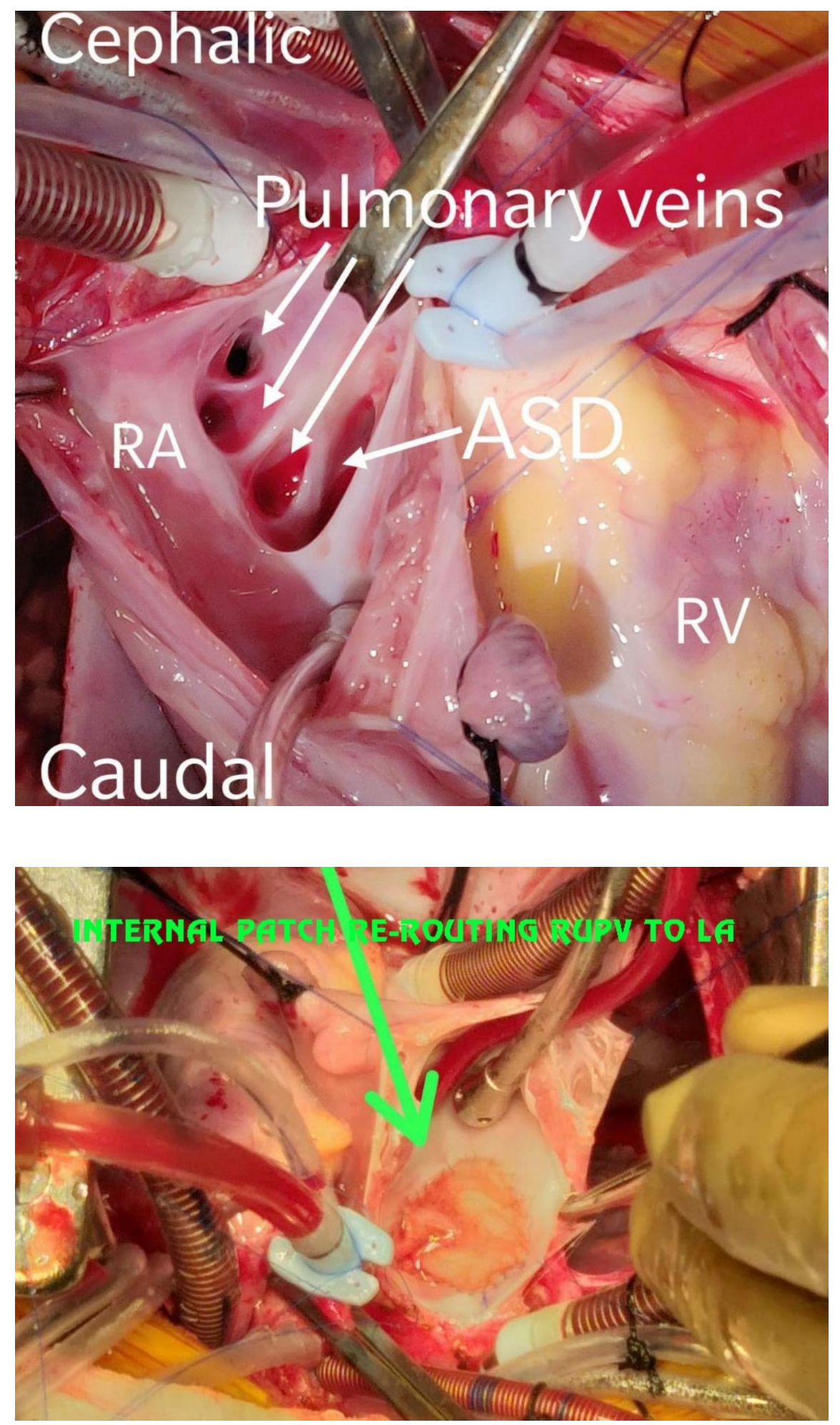

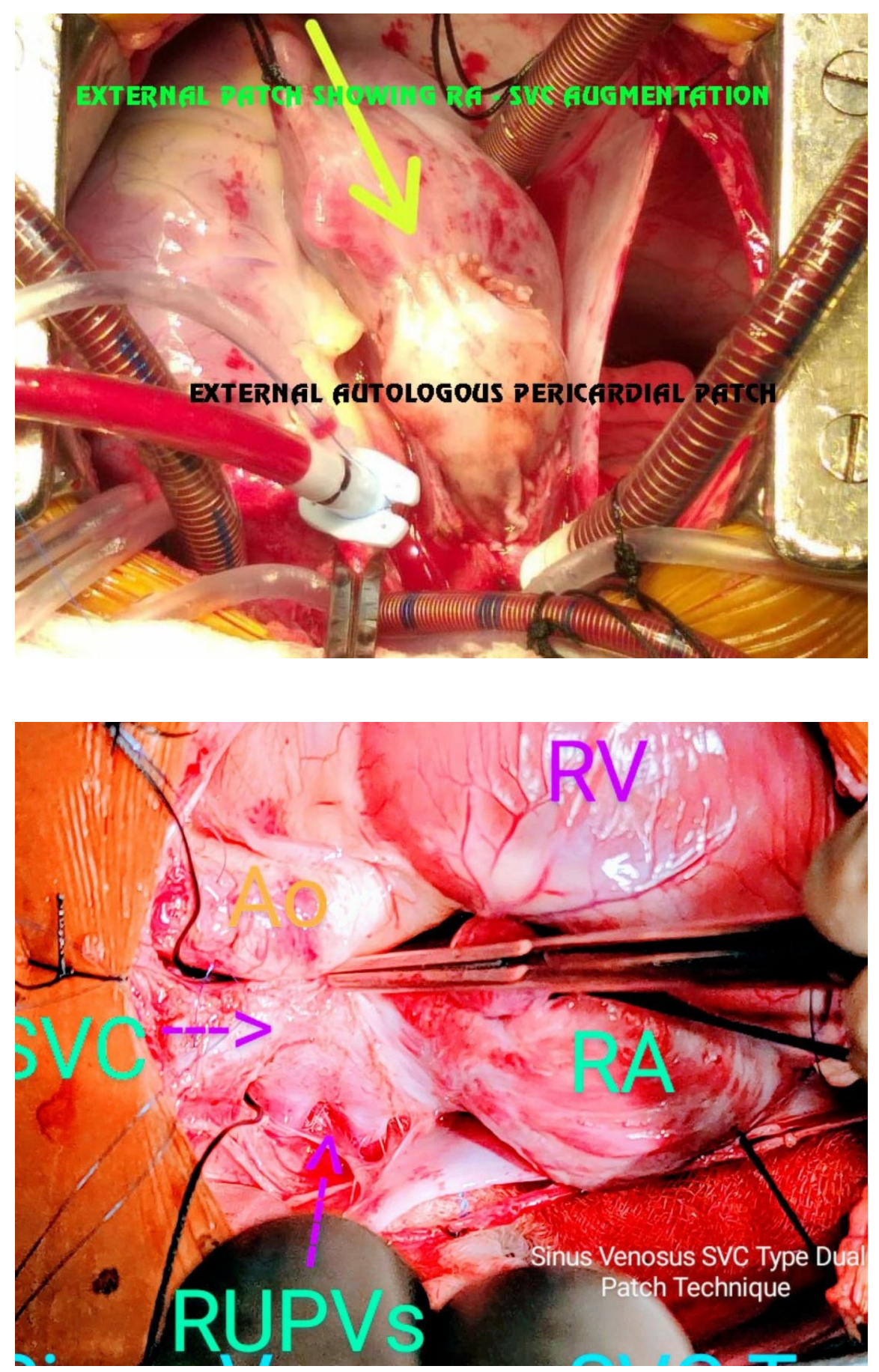


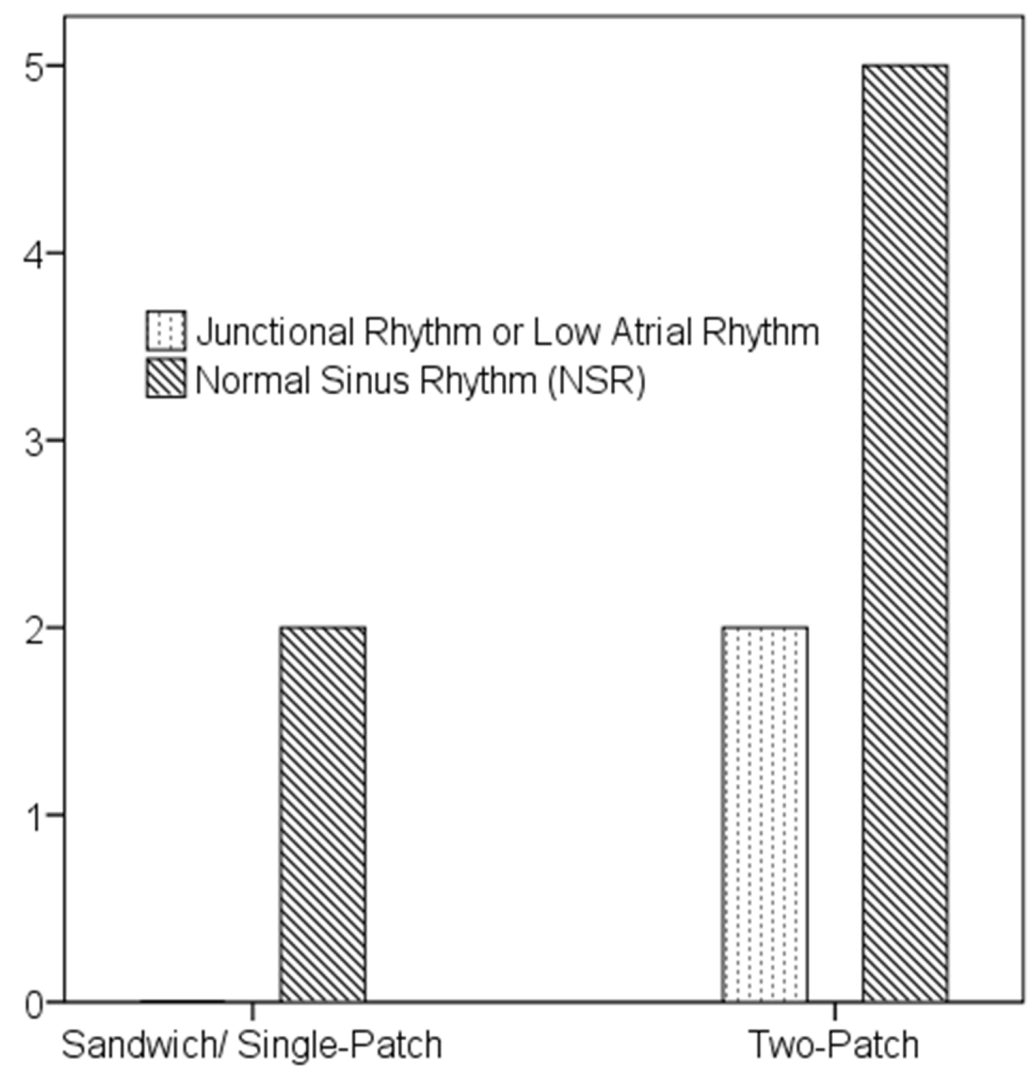




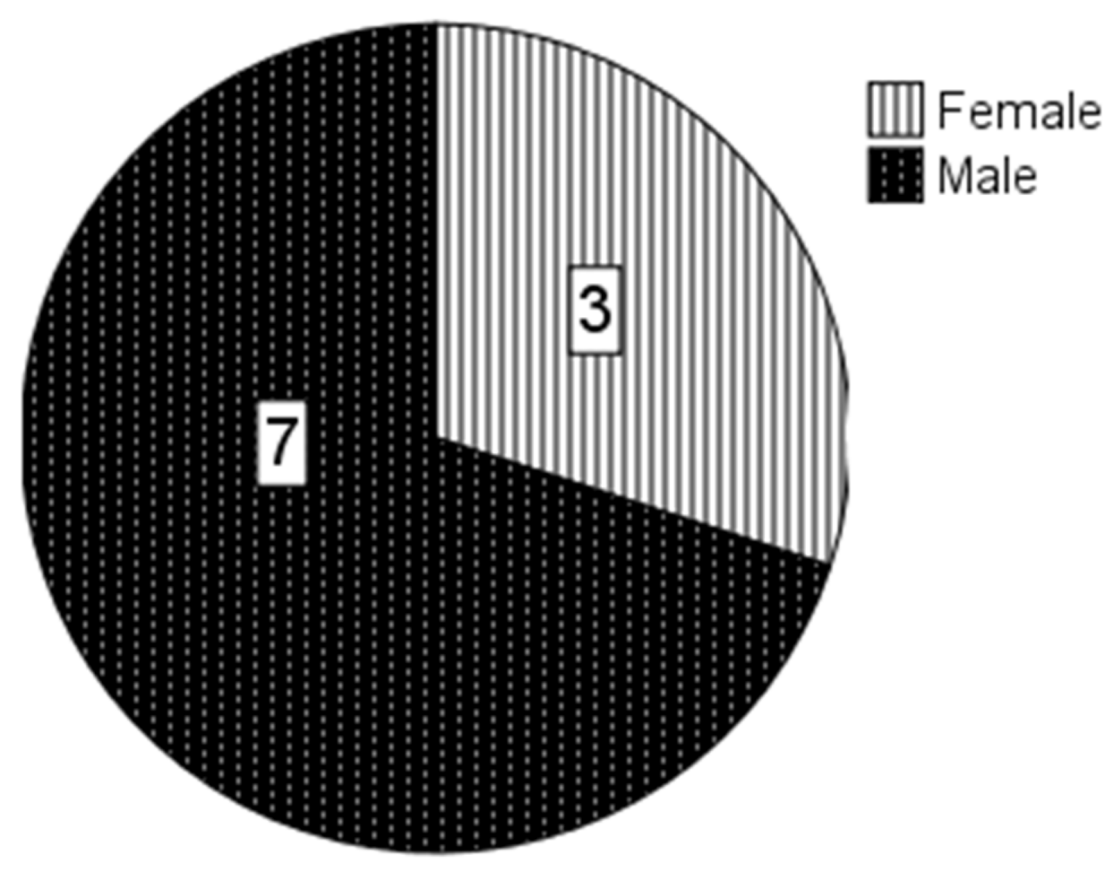

Gender wise Distribution

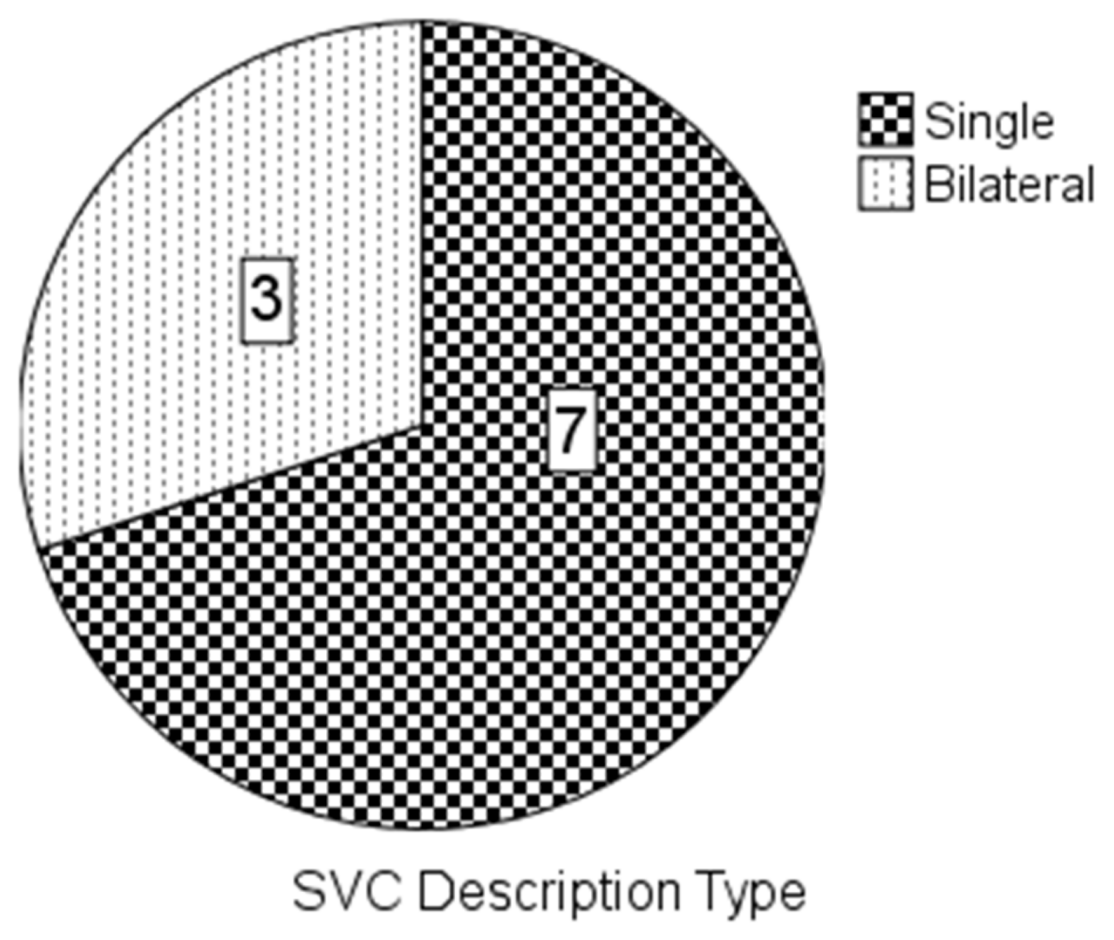



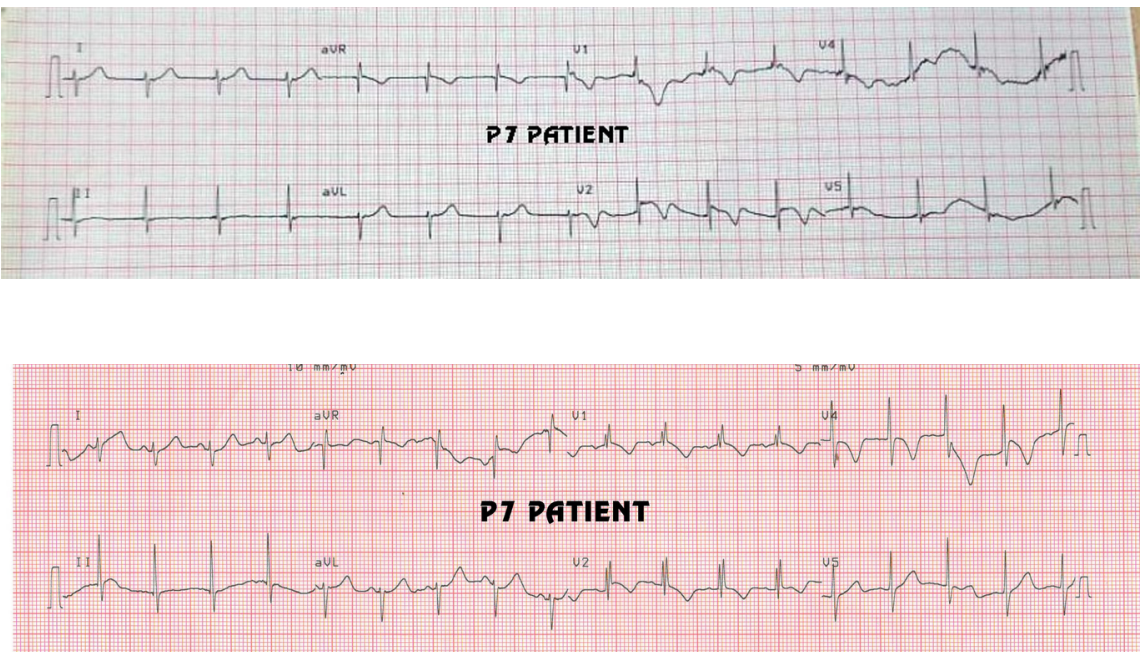

\section{Hosted file}

TABLE.docx available at https://authorea.com/users/454413/articles/552035-mid-term-postoperative-outcome-of-sinus-venosus-atrial-septal-defect-with-anomalous-pulmonary-venousconnection-with-different-surgical-strategies-and-their-effect-on-sinus-node-functionand-late-venous-obstruction 